\title{
Learning from accidents: interactions between human factors, technology and organisations as a central element to validate risk studies
}

\author{
R. Moura ${ }^{\mathrm{a}, \mathrm{d}}$, M. Beer ${ }^{\mathrm{b}, \mathrm{ac}}$, E. Patelli $^{\mathrm{a}}$ \& J. Lewis ${ }^{\mathrm{a}}$ \\ ${ }^{a}$ Institute for Risk and Uncertainty, University of Liverpool, United Kingdom \\ ${ }^{b}$ Institute for Computer Science in Civil Engineering, Leibniz University Hannover, Germany \\ ${ }^{c}$ Tongji University, Shanghai, China \\ ${ }^{d}$ National Agency for Petroleum, Natural Gas and Biofuels (ANP), Brazil
}

\author{
F. Knoll \\ NCK Inc., Montreal, Canada
}

\begin{abstract}
Many industries are subjected to major hazards, which are of great concern to stakeholders groups. Accordingly, efforts to control these hazards and manage risks are increasingly made, supported by improved computational capabilities and the application of sophisticated safety and reliability models. Recent events, however, have revealed that apparently rare or seemingly unforeseen scenarios, involving complex interactions between human factors, technologies and organisations, are capable of triggering major catastrophes. The purpose of this work is to enhance stakeholders' trust in risk management by developing a framework to verify if tendencies and patterns observed in major accidents were appropriately contemplated by risk studies. This paper first discusses the main accident theories underpinning major catastrophes. Then, an accident dataset containing contributing factors from major events occurred in high-technology industrial domains serves as basis for the application of a clustering and data mining technique (self-organising maps - SOM), allowing the exploration of accident information gathered from in-depth investigations. Results enabled the disclosure of common patterns in major accidents, leading to the development of an attribute list to validate risk assessment studies to ensure that the influence of human factors, technological issues and organisational aspects was properly taken into account.
\end{abstract}

\section{Introduction}

\subsection{Accident causation models and implications to validate risk assessments}

Accident causation models lie beneath all efforts related with safety engineering, as they serve as basis for accident investigation and analysis, to prevent future accidents in new designs and for the development of risk assessment techniques (Leveson, 2012). The rising interest in understanding the genesis of major accidents and the growing importance of technological issues to societies directed many schools of thought to approach the accident causation problem from different perspectives, leading, to a certain extent, to conflicting ideas on how (and if) hazards can be appropriately addressed and controlled.

According to Perrow (1984), failures in complex, tightly coupled systems are inevitable, and thus the occurrence of accidents with catastrophic potential in some high-technology facilities (e.g. nuclear 
power and nuclear weapons) is unavoidable, constituting an expected or normal accident. His theory was developed after the Three Mile Island accident, a partial core meltdown occurred in a USA nuclear power plant in 1979 which was his base case. To cut a long story short, he simply suggests the discontinuation of technologies such as nuclear plants and weapons (which he deems hopeless) as he understands that the inevitable risks outweigh the perceived benefits. Operator errors are frequent elements of the scrutinised case studies, highlighting how complex interactions of a series of failures can lead to flawed mental models. Perrow alludes to a sole possible managerial style to safely run these facilities: a military-shaped organisation, authoritarian and rigidly disciplined. However, he claimed that this administration structure would be socially intolerable and unsustainable during peacetime, for industrial civil activities.

The Normal Accidents Theory is preceded by Cohen's Garbage-Can Model (Cohen et al., 1972, Davis et al., 1988), which presented an earlier recognition that organisations have high degrees of uncertainty, leading to ill-defined or competing preferences, ambiguous goals, unclear technology and fluid patterns of stakeholders' involvement in the decision-making process. While the Garbage Can theory indicates that major accidents will happen because organisational behaviour is extremely complex and unpredictable, the Normal Accidents Theory limits the inevitability of disasters to systems where complexity and tight coupling are observed. Though both theories share an unenthusiastic view of the human capacity to predict and control hazards, yet some distinct (and useful) elements can be extracted from them: the former clearly points towards organisational matters as the root-cause of catastrophes, while the latter blames technological aspects, albeit assuming that it could be somehow mitigated by a particular type of military organisation.

Taleb's book The Black Swan - The Impact of the Highly Improbable (2007) minted a popular and wide-reaching concept (Aven, 2015, Aven 2013, Paté-Cornell, 2012) to explain the occurrence of major accidents. He refers to events with extreme impacts as Black Swans, considering them as highly improbable events (or outliers) which are not prospectively foreseeable. His celebrated analogy was based on the fact that people only knew white-feathered swans before the English arrival in Australia, where the sight of a black swan came as a surprise. He concludes that predictions based on historical data cannot anticipate outliers, claiming that the usual focus on standard operations disregards the extreme or uncertain. According to his views, the dynamics in hightechnology domains are far more complicated than can be anticipated, and conducting laborious pre-analysis and validation based on probabilistic modelling should be ruled out, as it has little effect in terms of major hazards control (or black swans prevention!).

It is worth to notice that many widespread accident causation theories appear to consider the successful operation of a high-risk industrial facility as a matter of good fortune, since major accidents are perceived to have a chaotic nature. According to this approach, preferences are being randomly defined, technologies are not fully understood by managers and workers, complex interactions leading to major accidents are not predictable and stakeholders' groups are fluctuating.

Conversely, researchers on High Reliability Organisations (Roberts, 1990, Grabowski \& Roberts, 1997, La Porte \& Consolini, 1998) address cases where organisations managing operations with high potential for disasters achieved excellent levels of reliability for long periods of time, appearing to function better than others. Based on the observation of success cases, they believe that it is 
possible to recognise scientific methods to sustain a nearly error-free operation, even in very hazardous environments. It is worth noticing that the examples used to ratify the High Reliability Organisations principles include nuclear power stations, putting it in sharp contrast with the Normal Accidents Theory. According to Perrow (1984), these are precisely the sort of facility susceptible to unavoidable failures, and thus society should consider abandoning it at once.

Sagan (1993) conducted an in-depth analysis of the Normal Accidents and the High Reliability Organisations theories, presenting some of the competing viewpoints below.

Table 1 - Competing Perspectives on Safety with Hazardous Technologies (Sagan, 1993)

\begin{tabular}{|l|l|}
\hline \multicolumn{1}{|c|}{ High Reliability Theory } & \multicolumn{1}{c|}{ Normal Accidents Theory } \\
\hline $\begin{array}{l}\text { Accidents can be prevented through good } \\
\text { organisational design and management. }\end{array}$ & $\begin{array}{l}\text { Accidents are inevitable in complex and tightly } \\
\text { coupled systems. }\end{array}$ \\
\hline Safety is the priority organizational objective. & Safety is one of a number competing objectives. \\
\hline $\begin{array}{l}\text { Redundancy enhances safety: duplication and overlap } \\
\text { can make "a reliable system out of unreliable parts". }\end{array}$ & $\begin{array}{l}\text { Redundancy often causes accidents: it increases } \\
\text { interactive complexity and opaqueness, and } \\
\text { encourages risk-taking. }\end{array}$ \\
\hline $\begin{array}{l}\text { Decentralized decision-making is needed to permit } \\
\text { prompt and flexible field-level responses to surprises. }\end{array}$ & $\begin{array}{l}\text { Organisational contradiction: decentralisation is } \\
\text { needed for complexity, but centralisation is needed } \\
\text { for tight-coupled systems. }\end{array}$ \\
\hline $\begin{array}{l}\text { A "culture of reliability" will enhance safety by } \\
\text { encouraging uniform and appropriate responses by } \\
\text { field-level operators. }\end{array}$ & $\begin{array}{l}\text { A military model of intense discipline, socialisation } \\
\text { and isolation is incompatible with democratic values. }\end{array}$ \\
\hline $\begin{array}{l}\text { Continuous operations, training and simulations can } \\
\text { create and maintain high-reliability operations }\end{array}$ & $\begin{array}{l}\text { Organisations cannot train for unimagined, highly } \\
\text { dangerous or politically unpalatable operations. }\end{array}$ \\
\hline $\begin{array}{l}\text { Trial and error learning from accidents can be } \\
\text { effective, and can be supplemented by anticipation } \\
\text { and simulations. }\end{array}$ & $\begin{array}{l}\text { Denial of responsibility, faulty reporting and } \\
\text { reconstruction of history cripples learning efforts. }\end{array}$ \\
\hline
\end{tabular}

Despite the evident disparity between these schools of thoughts, especially regarding the possibility of preventing a major accident, Sagan perceived some common ground regarding the frequencies of these events. While the normal accidents theory states that major accidents are inevitable, but extremely rare, high-reliability organisations theory postulates a nearly error-free operation by an enhanced safety management. Implicitly, there is a mutual recognition of the low probabilities of catastrophic events. After assessing several study cases on safety events involving U.S. nuclear weapon systems, Sagan (1993) concluded that the collected evidences provided stronger support to the Normal Accidents Theory. His observations indicated that factors such as excessive discipline (he identified evidences of extreme loyalty, secrecy, cover-ups, distain for external expertise and other self-protecting mechanisms), conflicting interests and constraints on learning have limited nuclear facilities' organisational safety and could have resulted in major catastrophes if circumstances were slightly different.

Therefore, Sagan's resulting analysis of the theories can be considered even more pessimistic than the Normal Accidents Theory. Despite the claim that accidents are inevitable, Perrow's left the door open for a social incompatible but safety-efficient managerial style: a military-shaped organisation with rigid discipline. However, his allegations were challenged by Sagan's nuclear weapons handling sample, which included an alarming number of close calls. 
Other researchers recognise the difficulties in preventing major accidents, but focus on the development of strategies to reduce their likelihood. Following this principle, James Reason developed an acclaimed and widely-known accident causation approach, which evolved from Heinrich's et al. (1980) Domino Theory. Reason (1990) firstly developed the idea of having a combination of active failures and latent conditions to explain how complex systems can fail, later expanding it to a multi-barrier concept known as the Swiss Cheese Accident Model (Reason, 1997), which is widely used by academics and practitioners to describe the dynamics of accident causation. Successive cheese slices represent layers of defences, barriers and safeguards, all containing holes symbolising breaches caused by active failures and latent conditions. In the rare occasions when holes are perfectly aligned and all protective layers are overcome, an organisational accident will occur, usually having devastating consequences. A vital distinction between individual accidents and organisational accidents was highlighted by the theory, especially the risk that organisations will be tempted to rely on LTI (lost-time injury) or Bird's pyramid-type methodologies to demonstrate safety performance, overlooking latent conditions that degrade barriers and lead to major accidents. Many risk management approaches derive from the multi-barrier concept developed by Reason, relying that the underlying mechanisms causing organisational accidents can be correctly identified and properly managed. Human reliability approaches such as Human Factors Analysis and Classification System - HFACS (Shappell et al., 2007), Systematic Occurrence Analysis Methodology - SOAM (Licu et al., 2007) and the Sequentially Outlining and Follow-up Integrated Analysis - SOFIA (Blajev, 2002), and accident causation analysis methods such as Bow-Tie (Zuijderduijn, 2000) and CauseConsequence Diagrams (Nielsen, 1971) are examples, to name but a few, of risk assessment techniques deeply aligned with Reason's approach.

Contemporary approaches on accidents causality models try to apply systems theory and system thinking (e.g. Leveson, 2011) to disclose deeper factors contributing to accidents, by adding higher hierarchical levels beyond immediate events and analysing the interactions among factors and broader circumstances. Examples are how public opinion and governments' movements influence the safety culture of an industrial segment. If the interaction among some of the constituent elements violates a set of constraints that guarantees the system safety integrity, an accident may occur. The focus of this systemic approach to accident causation is on understanding why the enforcement of constraints was unsuccessful.

A comparable perspective was previously conceived by Rasmussen's (1997) thoughts on system performance control. Instead of continually constrain individual elements to fit a pre-defined operational standard or limit, he focused on two features of system control theory: firstly, the need for adaptation of the system operation boundaries, i.e. increasing the margin from normal operation to loss-of-control; and secondly, increasing the awareness level of operational limits by making these boundaries visible to stakeholders. Rasmussen also noted that the pace of technology change is much faster than the modification time for management structures, and an even longer change lag is observed in higher hierarchical levels such as governments, regulations and society. This asynchrony defies risk modelling and challenges the rationale of using detailed methods and tools for analysing individual components or sub-systems, as system parts/components satisfactory results might not reflect the safety status of the overall system. 
When the utmost objective is the validation of risk assessments for hazardous industrial process plants in a dynamic and fast-changing environment, the complexity of the interactions among system elements must be recognised, along with the unpredictability of organisational behaviour and the inherent difficulties to prospectively foresee extremely rare, low-probability events, as highlighted by accident causation theorists. Additionally, designed safety barriers are not static and tend to degenerate through time. Factors such as ageing, maintenance shortcomings, budget constraints, personnel fluctuation and pressure towards to cost-effectiveness, to name but a few, can contribute to defeat barriers and thus defence-in-depth concepts, which largely serve as basis for risk assessment studies.

\subsection{Identifying common patterns and developing a risk assessment validation framework based on major accidents}

The fact that accidents causation theories disagree whether major events are preventable or not turns risk assessment validation and trust in risk management into a challenging research topic. Although any model will imply the reduction of the complexity of operational reality, some attributes can be extracted from accident causation models in order to establish an acceptable framework to verify the applicability and accurateness of risk management strategies.

It is disputed if the study of success cases, as argued by high-reliability organisations theorists, will give some insight into the unusual, rare interfaces observed in major accidents. In contrast, the identification of common patterns arising from interactions between human factors, technological aspects and organisations during catastrophic events seems to be a reasonable approach to subsidise a verification strategy for risk analysis, at least to certify that lessons learned from previous accidents were contemplated in current studies. This novel approach might help reducing the gap pointed out by Skogdalen and Vinnem (2012) when analysing a number of quantitative risk analysis from the Norwegian Oil \& Gas industry. They identified that human and organisational factors (HOFs) were not taken into account during the estimation of the probabilities of a blowout. In contrast, the Deepwater Horizon blowout was deeply associated with HOFs such as work practice, training, communication, procedures, quality control and management. Previous analysis of 238 major accidents (Moura et al., 2016) also indicated that 95\% of these events presented some sort of organisational contribution to the undesired outcome, and $57 \%$ were directly associated with human factors, highlighting the importance of considering these significant features to develop realistic safety studies.

Barrier and defences-in-depth concepts will rely on the integrity and availability of the designed barriers to hold hazards or to minimise their consequences. Addressing common organisational and technological shortcomings contributing to the degradation of critical safety barriers can reveal tendencies which make them fail upon demand. The pattern identification process would also support the application of a safety check against recurrent damage mechanisms, reducing latent failures and providing useful data to endorse the expected positive effect of the barrier during a real event.

The disclosure of common patterns leading to major accidents will make operational boundaries visible to stakeholders, improving confidence in the decisions made and justifying the application of 
additional safety measures. The fact that the output will be directly associated with real events will facilitate the learning process and highlight the significance of addressing the identified concerns.

Therefore, this research will focus on the development of a risk assessment validation scheme, based on the interactions between human factors, technological aspects and organisations during major accidents. The collection of events constitutes the Multi-Attribute Technological Accidents Dataset (MATA-D) introduced by Moura et al. (2016), which captured major accidents occurred in high-technology industrial domains (e.g. aviation, oil \& gas upstream, refineries and nuclear plants) and classified them under a common framework, the Contextual Control Model used as basis for Hollnagel's (1998) Cognitive Reliability and Error Analysis Method. This previous work presented one of the most complete statistical analysis of major accidents from different industrial segments in the open literature.

The application of an artificial neural network approach, specifically Kohonen's (2001) Selforganising Maps (SOM), will result in the conversion of complex accident data into 2-D risk maps. Events will be clustered by similarity, allowing the combined treatment of accidents with similar interactions but from distinct industrial segments. The development of the data visualisation provided by the SOM application will give rise to the development of a set of properties, attributes and recommendations for the verification of systems, safety barriers, human-machine interfaces and risk studies, enhancing risk perception and stakeholders' trust.

\section{Analysis Method}

Previous works have applied past accidents data to produce insight into the genesis of adverse events, in order to support researchers and practitioners by offering valuable contributions to the development of risk management strategies and to disclose contributing causes to accidents. Most of the existing datasets arouse from accident/incident data reporting systems, voluntarily developed by companies/associations (e.g. DNV-GL World Offshore Accident Database, International Association of Gas Producers Process Safety Events Data) or enforced by states (e.g. UN International Civil Aviation Organization Accident Indent Data Reporting system - ADREP, UK HSE's Reporting of Injuries, Diseases and Dangerous Occurrences Regulations - RIDDOR). These efforts to collect data are commonly limited to a single industrial segment (Baysari et al., 2008, Evans, 2011) or attempt to embrace from occupational accidents to process safety events (Bellamy, 2007, 2013). Generally, reporting systems also include a category called near-misses, which are hazardous occurrences that did not resulted in a loss/injury but had the potential to do so.

The events' scrutiny level during the data acquisition stage will involve some expected variations, as it will mostly depend on the consequences of the event and secondly on the societal interest in the subject. Consequently, near-misses will be directly reported by companies, with the regulating body using this compact data to develop performance indicators or to trigger further actions such as inspections. Regulators can investigate occupational accidents directly, or validate/rely on companies' internal investigation procedures. Major accidents usually capture the media's and societal attention, pushing governments and regulators to react accordingly. Due to the wide-range consequences observed, this type of event requires consistent investigation processes, usually undertaken by one or more regulators, independent investigation commissions or both. The 
European Safety, Reliability and Data Association (2015) has recently recognised that these events trigger comprehensive examinations concerning preventive and protective systems, along with a careful consideration of factors and surrounding conditions leading to accidents. An illustrative example would be the Transocean's drilling rig Deepwater Horizon blowout and explosion occurred in the Gulf of Mexico in April 2010, which was investigated by the licensee (BP, 2010), regulators (USCG, 2010, BOMRE, 2011), an independent agency (US-CSB, 2016) and academic study groups (CCRM, 2011). Beyond doubt, catastrophic events lead to meticulous examinations and produce very detailed data about the conditions in which operations were inserted. Attributable to this extraordinary level of scrutiny, the data produced is indisputably more reliable and complete than any alternative source of information regarding accident causation.

The current version of the MATA-D, containing 238 major accidents from different high-technology industries (e.g. aviation, hydrocarbons exploration and production, refining, chemical industry, nuclear) will be used as a data source for this research. The dataset framework comprises 53 factors distributed in three main categories: man, technology and organisation. The structured but comprehensive nature of the MATA-D framework allowed for the effective application of several data mining approaches in previous research (e.g. Doell et al., 2015, Moura et al., 2015a, 2015b), such as agglomerative clustering methods, association rule mining techniques and neural networks. Cross-industrial common patterns in major events as well as significant relationships among contributing factors were successfully disclosed.

In this work, key interfaces between human factors, technological aspects and organisations will be identified through the application of a suitable artificial neural network technique named SOM (Kohonen, 2001). This data mining approach is especially effective when an unsupervised method (i.e. the number of clusters or final categories in the output space are unknown) and the classification and visualisation of high-dimensional data are needed (Kohonen, 2013; Ultsch, 1993). Data mining efforts will result in the reduction from 53 dimensions (or contributing factors per accident) to two-dimensional maps. The 2-D SOM maps will be generated with the support of a specialised software (Viscovery ${ }^{\circledR}$ SOMine expert version), to enhance the features' visualisation and facilitate the interpretation of the SOM output.

After the application of the SOM algorithm, the clusters where the highest incidence of interfaces was identified during major accidents will become apparent. Further examination of the intricate relationship among contributing factors within the clusters of interest will reveal common patterns and accident tendencies, highlighting principles that must be taken into account when developing risk assessment studies. Further details on the SOM algorithm rationale and settings, the translation of data into maps and the clusters' validity for the specific application have been previously discussed in Moura et al. (XXXX).

The conversion of relevant interfaces in a set of principles will subsidise the validation of risk analysis and risk management documents, by applying the lessons learned from major accidents. Accordingly, a straightforward requirement list to be crosschecked against risk studies will be developed, and further implications to enhance stakeholders' trust will be then discussed. 


\section{Results}

The application of the SOM algorithm to the MATA-D dataset resulted in four different accident clusters containing dissimilar influencing factors, as shown in Figure 1. The contributing factors label sizes are proportional to their effect within the grouping. For example, the Inadequate Task Allocation factor in Cluster 1 (magenta) occupies 95\% of the total cluster area, while Wrong Place occupies $52.5 \%$, and the Incomplete Information frequency is $36.2 \%$. This is one example of the usage of the visualisation power of the clustering method to interpret accident data. Figure 1 synthetizes information from a $238 \times 53$ Matrix (number of major accidents $x$ possible contributing factor per event) in a single 2-D image.

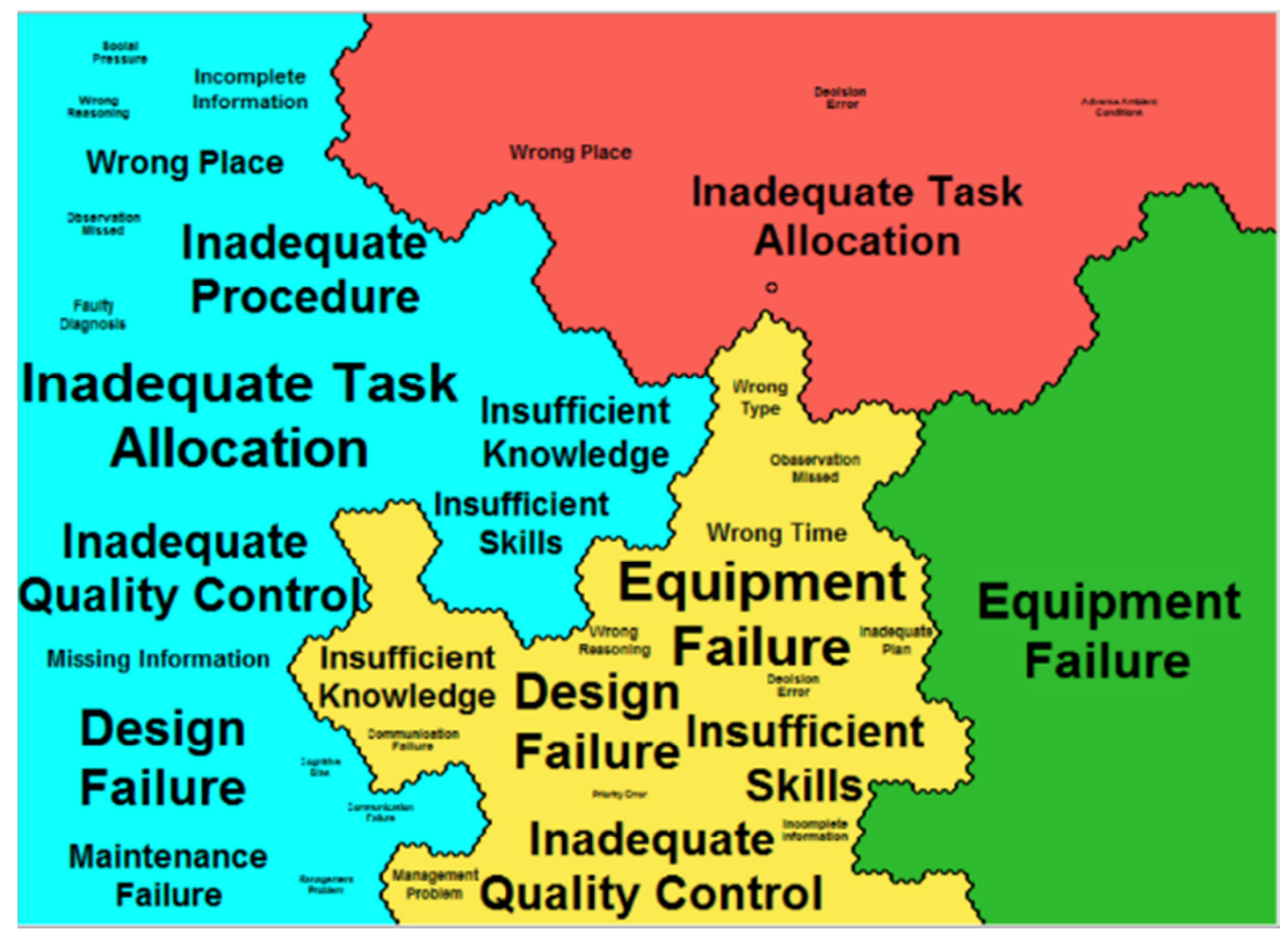

Figure 1 - MATA-D SOM Clustering output labelled by most relevant contributing factors

First cluster (magenta) covered $35 \%$ of the SOM map area, containing the highest amount of datapoints, with $34 \%$ of the accidents. Cluster 2 (red) has $25 \%$ of the total area and $24 \%$ of the dataset. The third grouping (yellow) occupies $20 \%$ of the total area and has the lowest event's frequency, with $16 \%$. Cluster 4 (green) also holds $20 \%$ of the map area, but embraces $26 \%$ of the dataset events. Figure 2 depicts the rate of contributing factors per event, discriminated by clusters. 


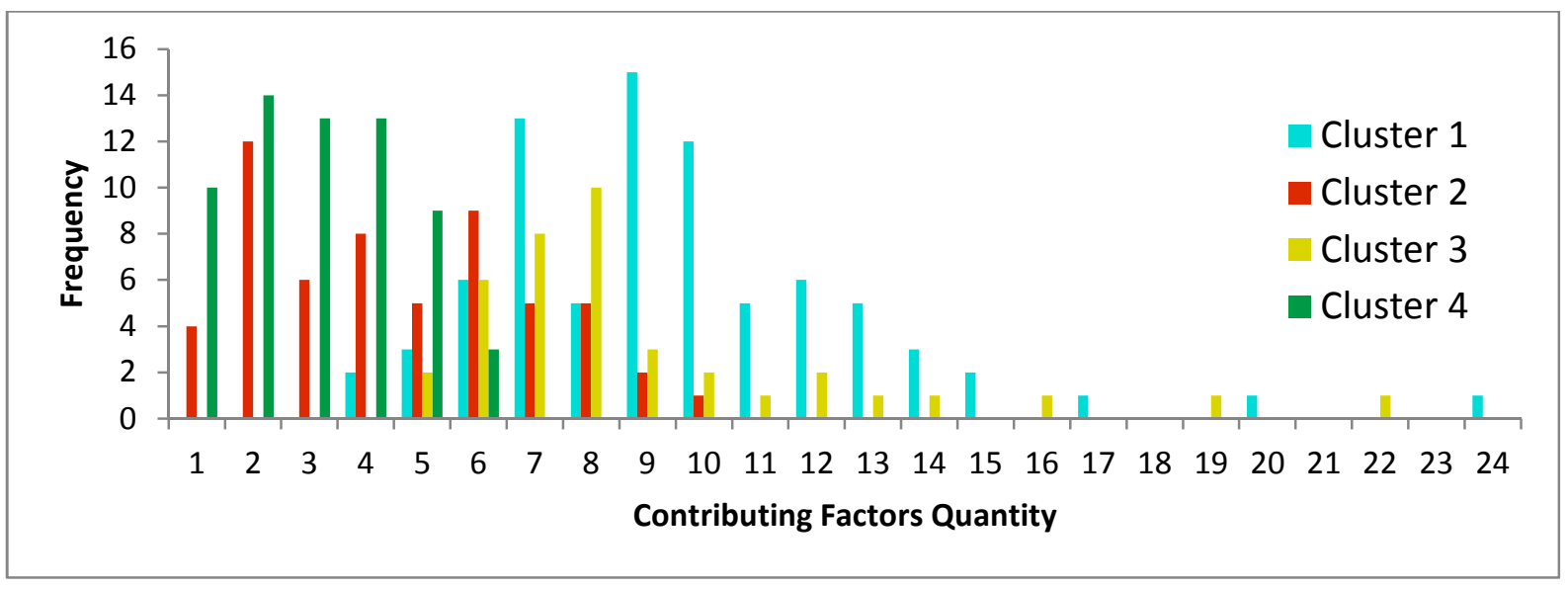

Figure 2 - Number of Contributing Factors Histogram

Figure 2 shows Cluster's 1 events with 4 to 24 contributing factors per accident and mode of 9, as it appeared in 15 events. 86.2\% of the accidents within this cluster have seven or more contributing factors, constituting a very rich grouping for further interpretation. Cluster 2 events were influenced by 1 to 10 features with $72.2 \%$ of the grouping having 6 or less contributing factors, while the totality of the events in Cluster 4 are constituted by 6 or less features. Both groupings show the same low mode of 2 factors, indicating a lower prospect for the identification of multiple interactions among contributing factors. For Cluster 3 , the total number of contributing factors per accidents varied from 5 to $22.79 .5 \%$ of the events contained seven or more contributing factors, being 8 factors the mode value. This grouping also tends to provide good opportunities for enhanced interpretations of the genesis of major accidents.

Results show that the application of the SOM algorithm largely improved the visualisation of interfaces, by confining events with lower frequency of contributors in clusters 2 and 4 , as well as elevating the features' mode for clusters 1 and 3, highlighting special structures within the dataset.

Table 2 details the results of the SOM clustering, indicating the effect of the data mining process to contributing factors, in relation to the overall dataset. The variation columns compare the overall dataset statistics with the individual factors' influence in each cluster. Negative or very low variations are not indicated, as the preservation or reduction of the frequency of a contributing factor in a grouping (in relation to its overall incidence) means that the factor was not significant to the formation of the cluster. 27 features contributed to less than $10 \%$ of the individual clusters and will not be represented, due to their low significance to the groupings formation. Contributing factors with strong dominance (more than $50 \%$ of the individual cluster areas) are highlighted, as well as frequencies higher than $10 \%$ and with positive cluster effect.

Table 2. Dataset overall statistics vs. clustering distribution for significant features

\begin{tabular}{|l|c|c|c|c|c|c|c|c|c|}
\hline $\begin{array}{c}\text { Contributing } \\
\text { Factor }\end{array}$ & Overall & C1 & Effect & C2 & Effect & C 3 & Effect & C 4 & Effect \\
\hline Wrong Time & $14.7 \%$ & $13.8 \%$ & - & $10.5 \%$ & - & $\mathbf{4 1 . 0 \%}$ & $+178.8 \%$ & $3.2 \%$ & - \\
\hline Wrong Type & $11.8 \%$ & $11.3 \%$ & - & $7.0 \%$ & - & $\mathbf{3 0 . 8} \%$ & $+161.8 \%$ & $4.8 \%$ & - \\
\hline
\end{tabular}




\begin{tabular}{|c|c|c|c|c|c|c|c|c|c|}
\hline Wrong Place & $31.5 \%$ & $52.5 \%$ & $+66.6 \%$ & $36.8 \%$ & $+16.8 \%$ & $12.8 \%$ & - & $11.3 \%$ & - \\
\hline $\begin{array}{l}\text { Observation } \\
\text { Missed }\end{array}$ & $15.5 \%$ & $20.0 \%$ & $+28.6 \%$ & $12.3 \%$ & - & $23.1 \%$ & $+48.6 \%$ & $8.1 \%$ & - \\
\hline Faulty diagnosis & $13.0 \%$ & $26.3 \%$ & $+101.9 \%$ & $8.8 \%$ & - & $12.8 \%$ & - & $0.0 \%$ & - \\
\hline $\begin{array}{l}\text { Wrong } \\
\text { reasoning }\end{array}$ & $11.3 \%$ & $20.0 \%$ & $+76.3 \%$ & $1.8 \%$ & - & $25.6 \%$ & $+125.7 \%$ & $0.0 \%$ & - \\
\hline Decision error & $9.2 \%$ & $5.0 \%$ & - & $17.5 \%$ & $+89.3 \%$ & $17.9 \%$ & $+93.6 \%$ & $1.6 \%$ & - \\
\hline Inadequate plan & $9.7 \%$ & $10.0 \%$ & - & $7.0 \%$ & - & $25.6 \%$ & $+164.9 \%$ & $1.6 \%$ & - \\
\hline Priority error & $7.1 \%$ & $6.3 \%$ & - & $8.8 \%$ & $+23.2 \%$ & $15.4 \%$ & $+115.6 \%$ & $1.6 \%$ & - \\
\hline Distraction & $5.9 \%$ & $11.3 \%$ & $+92.1 \%$ & $3.5 \%$ & - & $7.7 \%$ & $+30.9 \%$ & $0.0 \%$ & - \\
\hline Cognitive bias & $7.1 \%$ & $15.0 \%$ & $+110.0 \%$ & $1.8 \%$ & - & $10.3 \%$ & $+44.2 \%$ & $0.0 \%$ & - \\
\hline $\begin{array}{l}\text { Equipment } \\
\text { failure }\end{array}$ & $55.0 \%$ & $33.8 \%$ & - & $22.8 \%$ & - & $94.9 \%$ & $+72.4 \%$ & $87.1 \%$ & $+58.2 \%$ \\
\hline $\begin{array}{l}\text { Inadequate } \\
\text { procedure }\end{array}$ & $44.1 \%$ & $78.7 \%$ & $+78.4 \%$ & $42.1 \%$ & - & $38.5 \%$ & - & $4.8 \%$ & - \\
\hline $\begin{array}{l}\text { Incomplete } \\
\text { information }\end{array}$ & $17.6 \%$ & $36.2 \%$ & $+105.1 \%$ & $7.0 \%$ & - & $20.5 \%$ & $+16.2 \%$ & $1.6 \%$ & - \\
\hline $\begin{array}{l}\text { Communication } \\
\text { failure }\end{array}$ & $10.5 \%$ & $16.3 \%$ & $+55.2 \%$ & $5.3 \%$ & - & $20.5 \%$ & $+95.2 \%$ & $1.6 \%$ & - \\
\hline $\begin{array}{l}\text { Missing } \\
\text { information }\end{array}$ & $20.6 \%$ & $37.5 \%$ & $+82.1 \%$ & $14.0 \%$ & - & $15.4 \%$ & - & $8.1 \%$ & - \\
\hline $\begin{array}{l}\text { Maintenance } \\
\text { failure }\end{array}$ & $34.9 \%$ & $56.3 \%$ & $+61.4 \%$ & $14.0 \%$ & - & $33.3 \%$ & - & $27.4 \%$ & - \\
\hline $\begin{array}{l}\text { Inadequate } \\
\text { quality control }\end{array}$ & $60.9 \%$ & $81.3 \%$ & $+33.4 \%$ & $24.6 \%$ & - & $79.5 \%$ & $+30.5 \%$ & $56.5 \%$ & - \\
\hline $\begin{array}{l}\text { Management } \\
\text { problem }\end{array}$ & $9.2 \%$ & $12.5 \%$ & $+35.2 \%$ & $5.3 \%$ & - & $23.1 \%$ & $+149.9 \%$ & $0.0 \%$ & - \\
\hline Design failure & $66.0 \%$ & $85.0 \%$ & $+28.9 \%$ & $50.9 \%$ & - & $87.2 \%$ & $+32.2 \%$ & $41.9 \%$ & - \\
\hline $\begin{array}{l}\text { Inadequate } \\
\text { task allocation }\end{array}$ & $60.1 \%$ & $95.0 \%$ & $+58.1 \%$ & $68.4 \%$ & $+13.8 \%$ & $48.7 \%$ & - & $14.5 \%$ & - \\
\hline Social pressure & $7.1 \%$ & $17.5 \%$ & $+145.0 \%$ & $3.5 \%$ & - & $0.0 \%$ & - & $1.6 \%$ & - \\
\hline $\begin{array}{l}\text { Insufficient } \\
\text { skills }\end{array}$ & $36.1 \%$ & $56.3 \%$ & $+55.8 \%$ & $12.3 \%$ & - & $76.9 \%$ & $+112.8 \%$ & $6.5 \%$ & - \\
\hline $\begin{array}{l}\text { Insufficient } \\
\text { knowledge }\end{array}$ & $35.3 \%$ & $60.0 \%$ & $+70.0 \%$ & $17.5 \%$ & - & $56.4 \%$ & $+59.8 \%$ & $6.5 \%$ & - \\
\hline $\begin{array}{l}\text { Adverse } \\
\text { ambient } \\
\text { conditions }\end{array}$ & $7.1 \%$ & $2.5 \%$ & - & $14.0 \%$ & $+96.0 \%$ & $10.3 \%$ & $+44.2 \%$ & $4.8 \%$ & - \\
\hline $\begin{array}{l}\text { Irregular } \\
\text { working hours }\end{array}$ & $3.8 \%$ & $10.0 \%$ & $+164.4 \%$ & $1.8 \%$ & - & $0.0 \%$ & - & $0.0 \%$ & - \\
\hline
\end{tabular}

Figure 3 summarises the most relevant contributing factors to the formation of the clusters, rearranged by categories according to the dataset framework. 


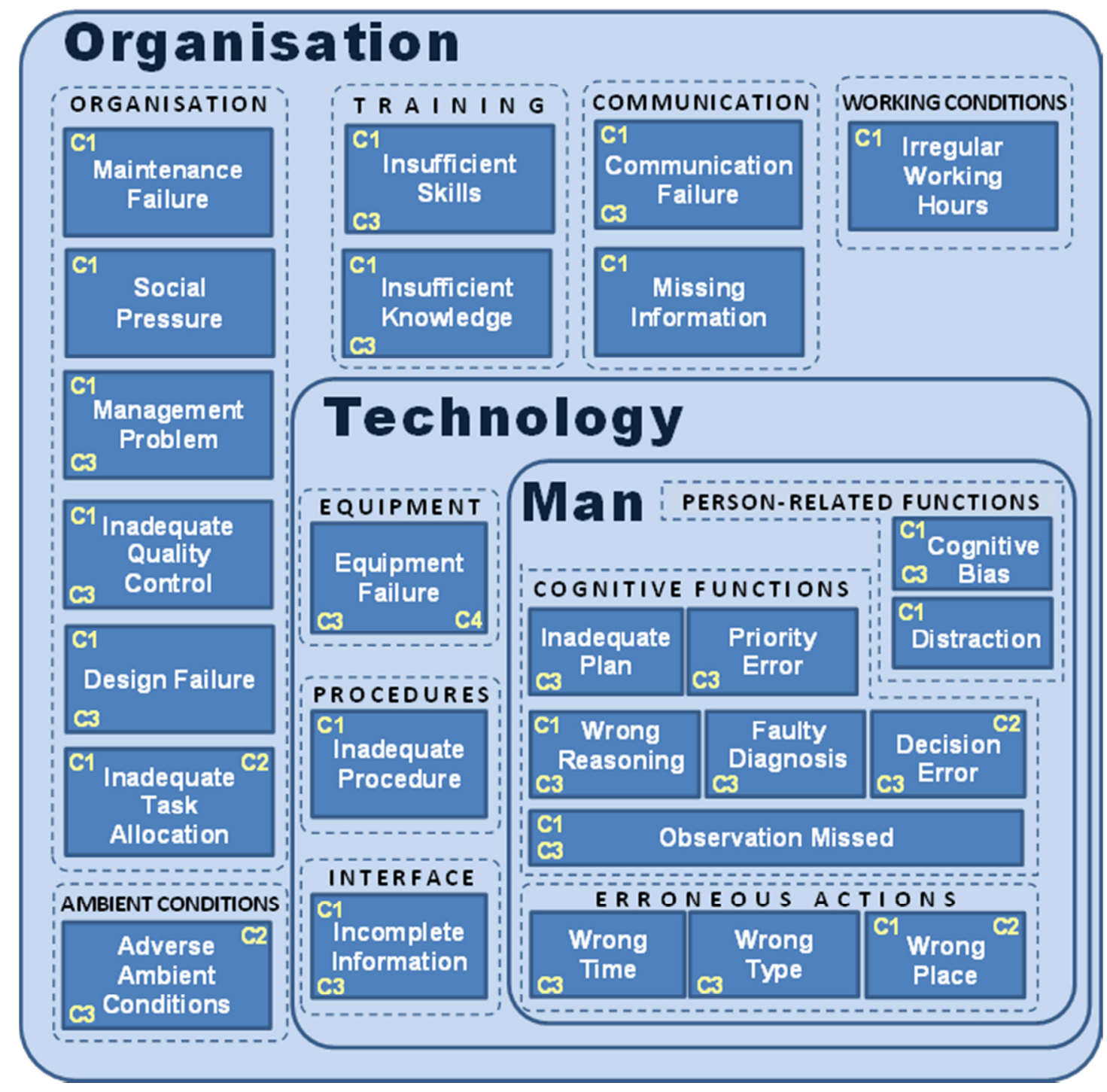

Figure 3 - Categories of the most significant contributing factors per cluster

From a human factors perspective, Cluster 1 accidents were dominated by the Wrong Place phenotype, when an action from an expected sequence is skipped, carried out in the incorrect order or substituted by an unrelated movement. Action errors interfaced with intermediate levels of human cognition, as operators were required to observe a signal or event (observation missed) and diagnose a situation or system state (faulty diagnosis). Inference or deduction errors (wrong reasoning) were also observed. This was the grouping where person-related features were more significant, as shifts in attention (distraction) or constraining the information search to confirm a predefined hypothesis, attributing events to specific factors or believing that actions have controlled the system state developments (cognitive bias) contributed to $11.3 \%$ and $15 \%$ of the cluster, respectively. Technology issues included procedure shortcomings (78.7\% of the cluster) and situations where the information provided by the system interface was poor (incomplete information). Many organisational issues interacted within the cluster. Inadequate Task Allocation (95\%), Design Failure (85\%) and Inadequate Quality Control (81.3\%) were the most significant ones, but training (Insufficient Skills and Insufficient knowledge) and communication issues 
(Communication Failure and Missing information) were considerable as well. Maintenance issues were visible in $56.3 \%$ of the cluster, and the effects of other organisational aspects such as social pressure (17.5\%), management problem (12.5\%) and irregular working hours (10\%) were also majored by the application of the clustering technique.

Cluster 2 has Inadequate Task Allocation as the most relevant factor, covering $68.4 \%$ of the grouping, followed by an erroneous action (Wrong Place) associated with an inability to decide, a partial/incomplete decision or making the wrong decision among alternatives (decision error). Accidents where Adverse Ambient Conditions were significant are mostly grouped within this cluster.

As indicated by Figure 2 histogram, Cluster 3 shows several important interactions among contributing factors, being a rich grouping for further interpretation. Many action errors were captured during the investigation of these events, where movements were performed earlier or later then required (Wrong Time), or with insufficient force, wrong speed, direction or magnitude (Wrong Type). Erroneous actions were accompanied by all three levels of cognition (observation, interpretation and planning). The fact that complex cognitive functions such as Inadequate Plan (25.6\%) and Priority Error (15.4\%) contributed to the formation of the cluster, together with observation missed (23.1\%), wrong reasoning $(25.6 \%)$ and decision errors (17.9\%), gives us an opportunity to understand how cognitive functions leading to erroneous actions interact with organisational and technological aspects. Equipment failures contributed to almost the totality of the grouping. As in Cluster 1, Design Failure, Inadequate Quality Control and training (Insufficient Skills and Insufficient Knowledge) records were very high, and other aspects such as incomplete information and communication failure were also significant for both groupings. Management problems were observable in $23.1 \%$ of Cluster 3.

Cluster 4 is largely dominated by Equipment Failures (87.1\%), the only noteworthy factor to influence the formation of grouping.

Figures 4 to 22 represent the cluster results for individual features. Blue areas indicate the absence of the contributing factor, while red areas represent its manifestation. Two graphical methods will be used to present individual maps and highlight the main results for further discussion:

(i) Disclosing multiple intersections (superposition of images) of the most frequent contributing factors, which represent strong interaction patterns between human factors, technology and organisations (e.g. Figures 4 to 10 and 18 to 22); and

(ii) analysis of special features (e.g. communication issues in Figures 11 to 14, humanrelated factors in Figures 15 to 17).

In Cluster 1, three map regions (1A, 1B and $1 \mathrm{C})$ represent the intersection between Inadequate Task Allocation, Design Failure, Inadequate Quality Control and Inadequate Procedure (Figures 4 to 7). Region $1 \mathrm{~A}$ is deeply related to Insufficient Knowledge (Figure 8 ), while $1 \mathrm{~B}$ is mostly associated with Insufficient Skills (Figure 9). Accidents represented in $1 \mathrm{C}$ tend to combine with Maintenance Failures (Figure 10). 


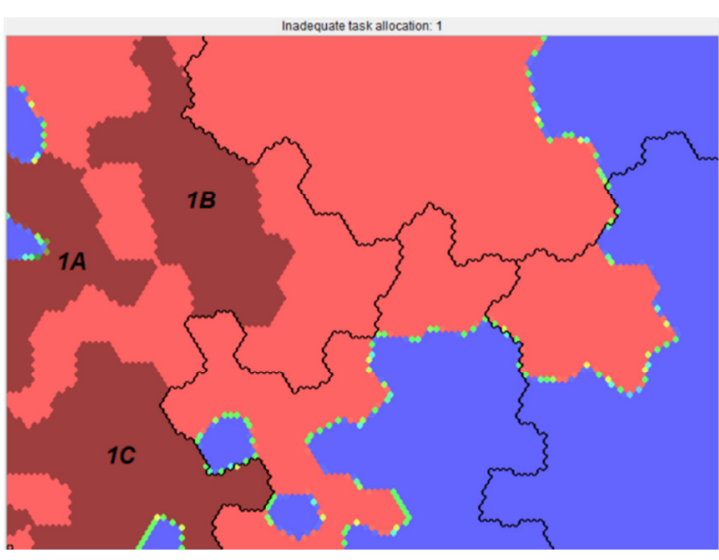

Figure 4 - Inadequate Task Allocation Map

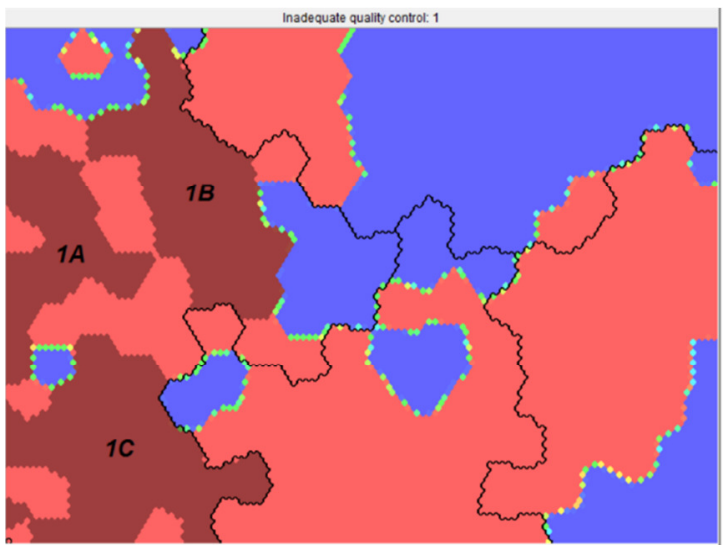

Figure 6 - Inadequate Quality Control Map

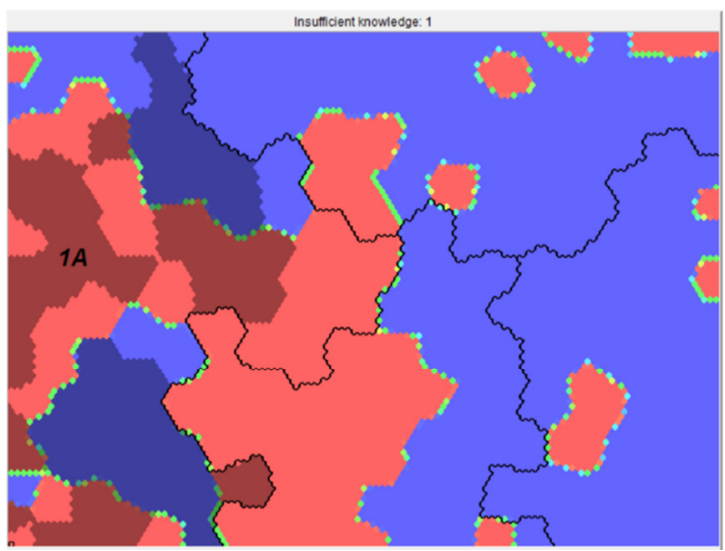

Figure 8 - Insufficient Knowledge Map

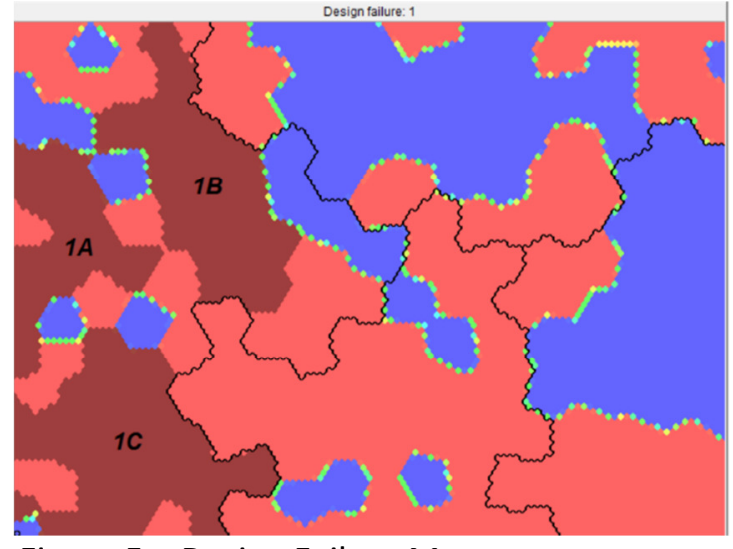

Figure 5 - Design Failure Map

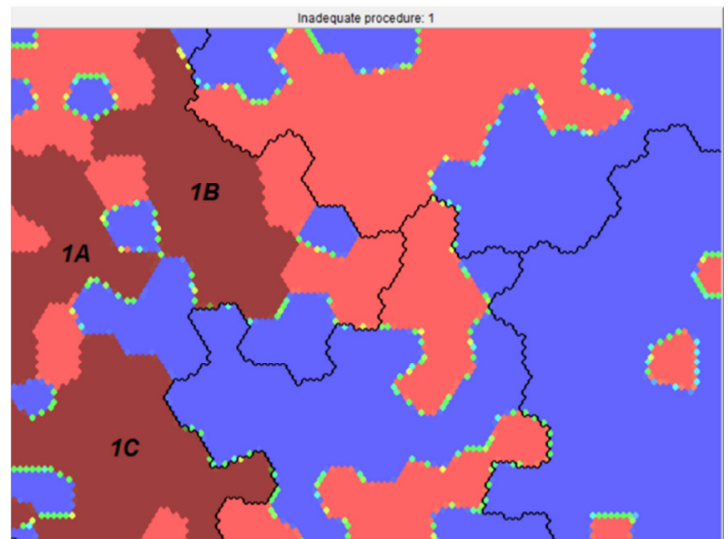

Figure 7 - Inadequate Procedure Map

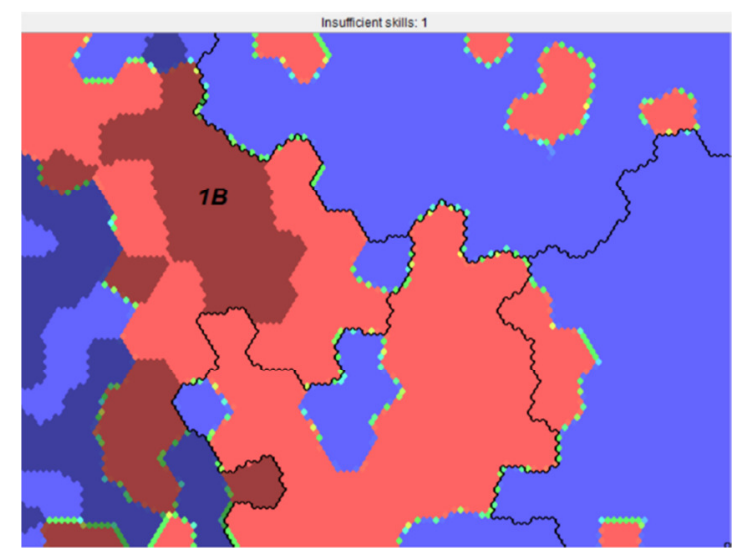

Figure 9-Insufficient Skills Map 


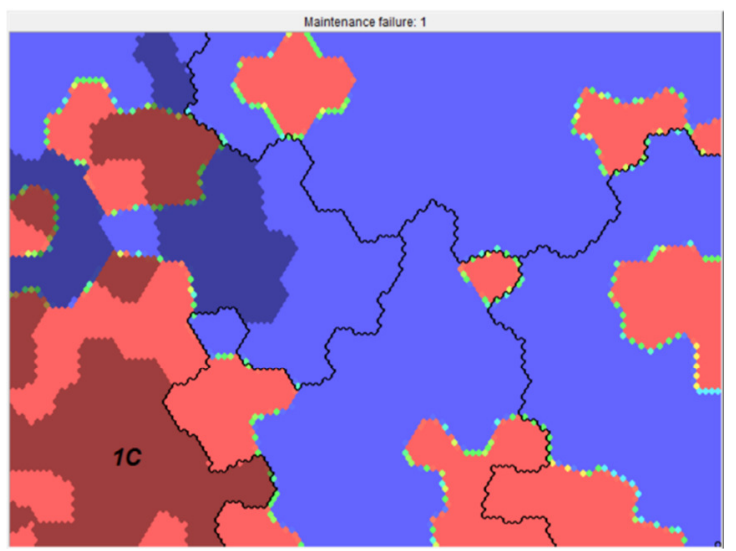

Figure 10 - Maintenance Failure Map

Figures 11 and 12 present the SOM maps for communication issues. These issues largely overlapped Inadequate Task Allocation in Cluster 1 , as can be seen in the shadowed region in Figure 13. Exceptions are the two small circled areas, where task allocation issues were substituted by the person-related feature named Cognitive Bias (Figure 14).

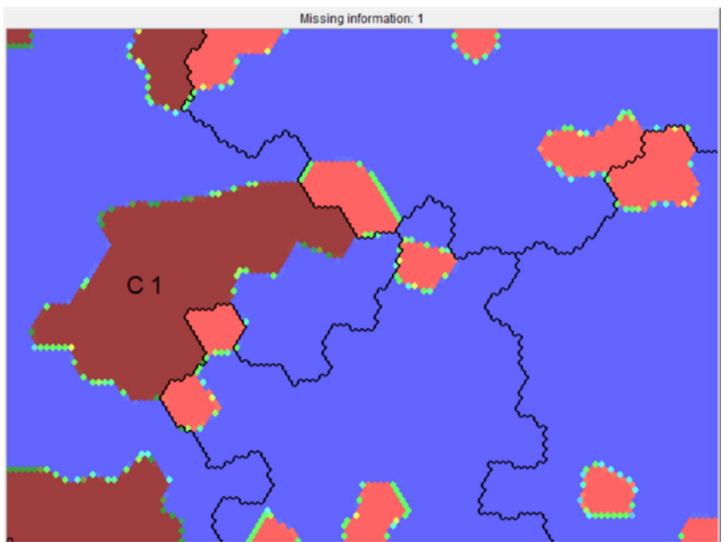

Figure 11 - Missing Information Map

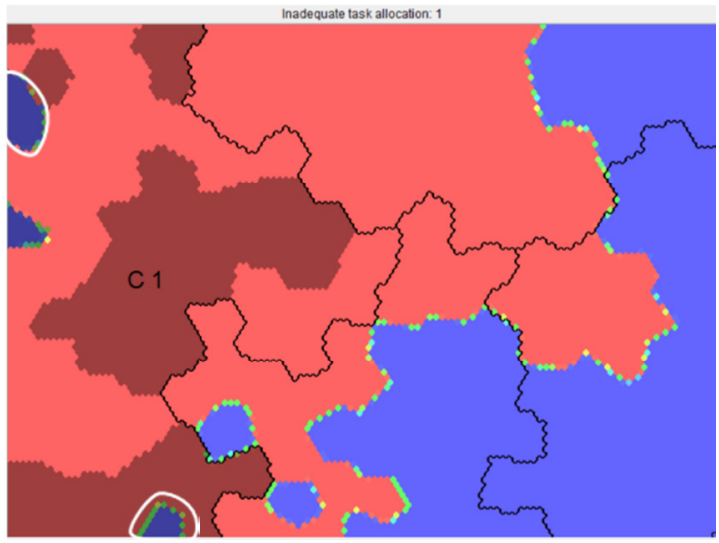

Figure 13 - Inadequate Task Allocation Map

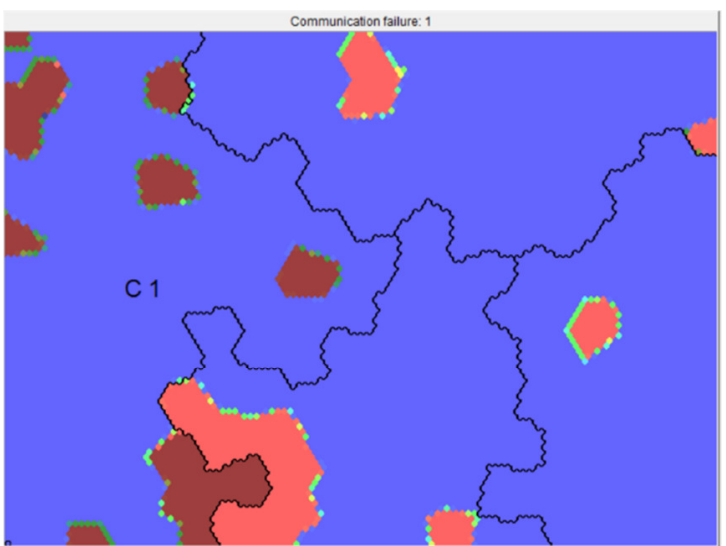

Figure 12 - Communication Failure Map

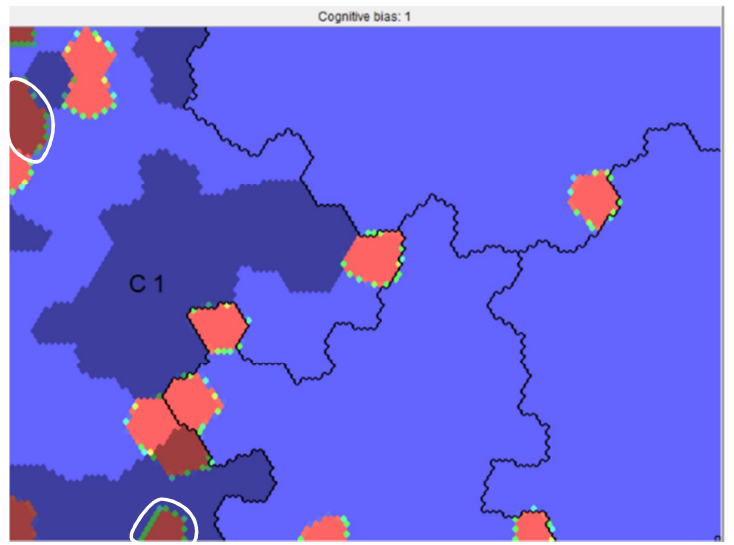

Figure 14-Cognitive Bias Map 
64.1\% of Cluster's 3 area contained two erroneous actions: Wrong Time (Figure 15) and Wrong Type (Figure 16). The faded region depicts the incidence of the three levels of specific cognitive factors within this grouping, showing the human-related contributing factors' representation. Consequently, a combination of observation (Observation Missed), interpretation (Wrong reasoning and Decision Error) and mental planning (Inadequate Plan and Priority Error) was expected to take place, suggesting that a profounder judgement of the confronted situation was necessary to solve system deviations. It can be observed that a technological issue (Incomplete Information - Figure 17) interacted with erroneous actions related to timing in the regions where a specific cognitive functions are not identified, suggesting that supervisory control system and data display limitations led to some of the Wrong Time occurrences. These areas are circled in Figure 15.

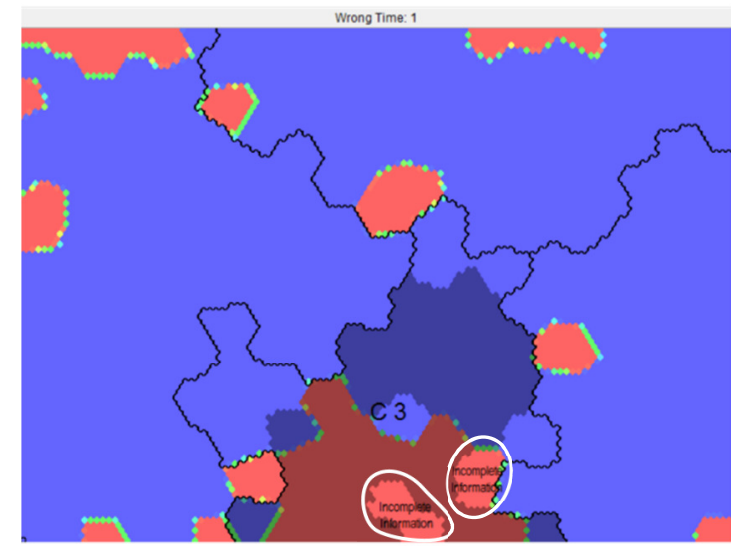

Figure 15 - Wrong Time Map

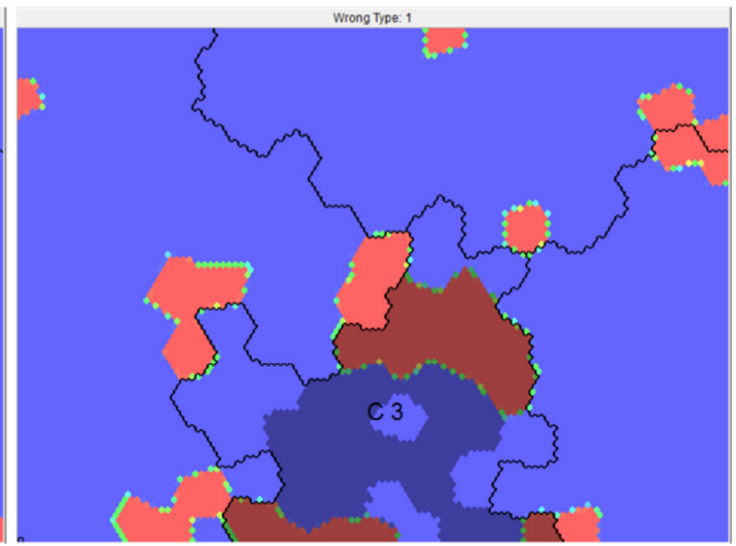

Figure 16 - Wrong Type Map

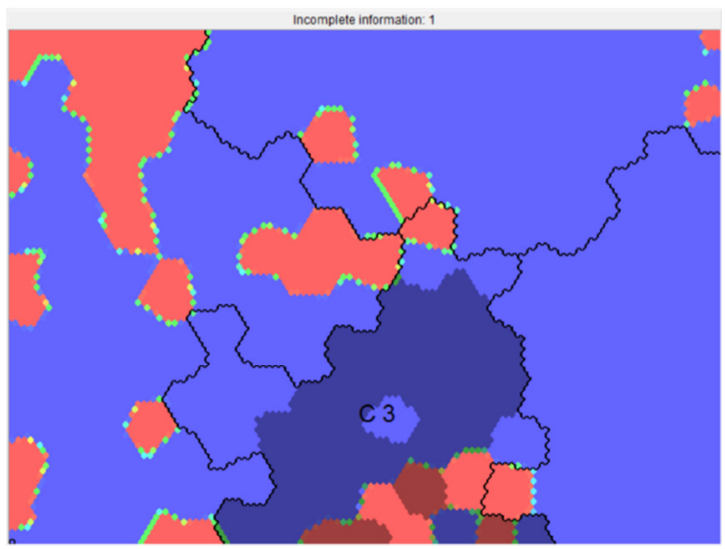

Figure 17 - Incomplete Information Map

Figures 18 to 22 show how the main technological (Equipment Failure) and organisational aspects (Quality Control, Design Failure and training) interacted among them and with human-related issues (shadowed region) to result in system control problems within Cluster 3. The shaded region is $79.5 \%$ 
of the grouping area, representing the incidence of human erroneous actions, specific cognitive functions and person-related functions.

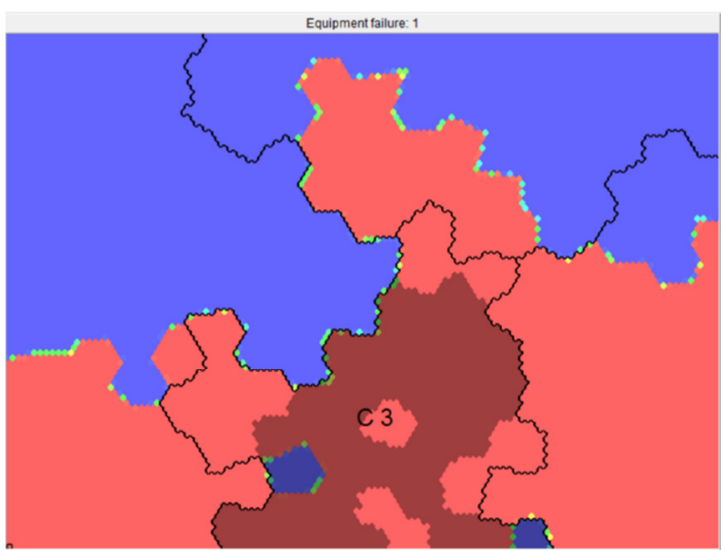

Figure 18 - Equipment Failure Map

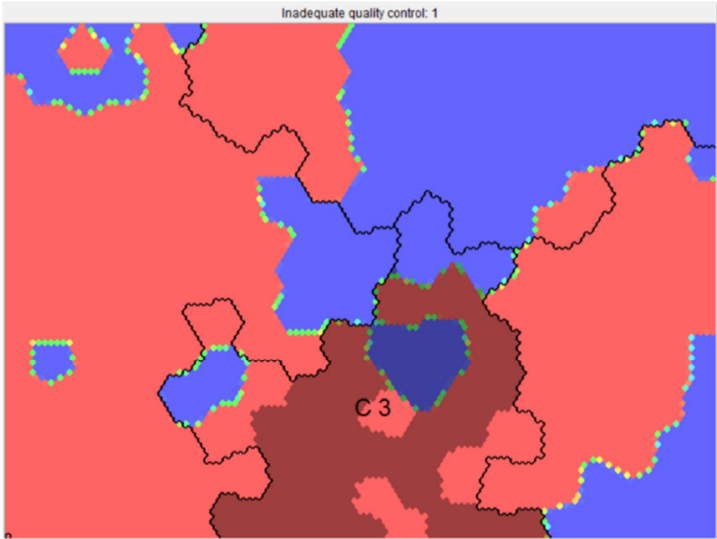

Figure 19 - Inadequate Quality Control Map

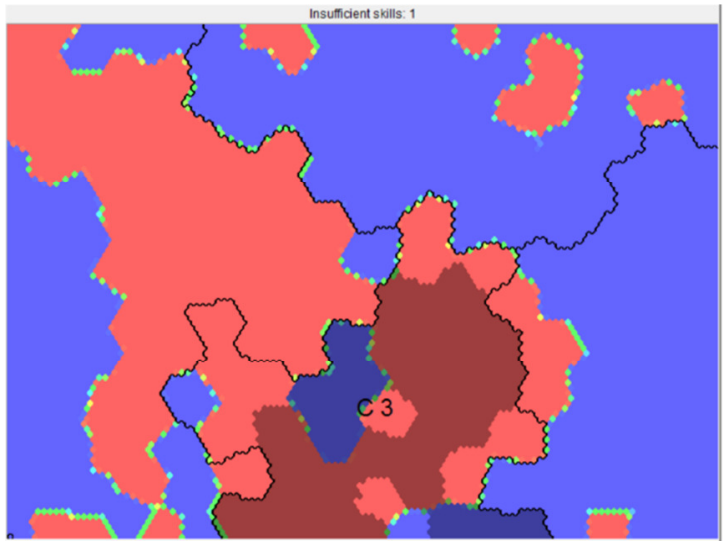

Figure 21 - Insufficient Skills Map

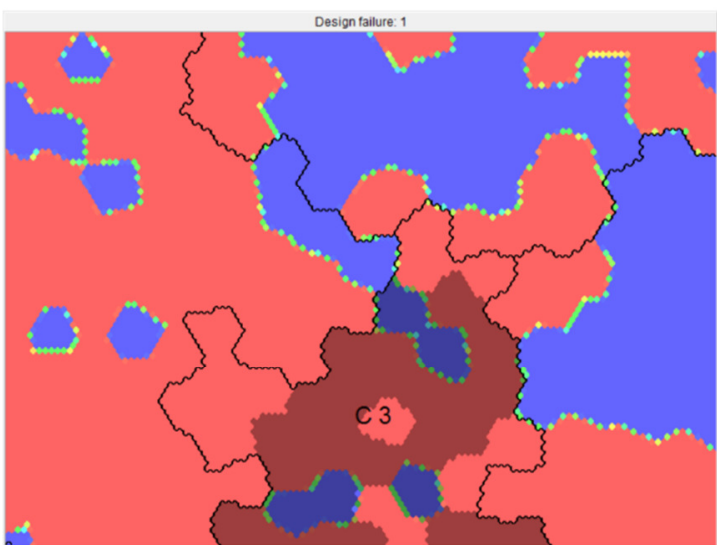

Figure 20 - Design Failure Map

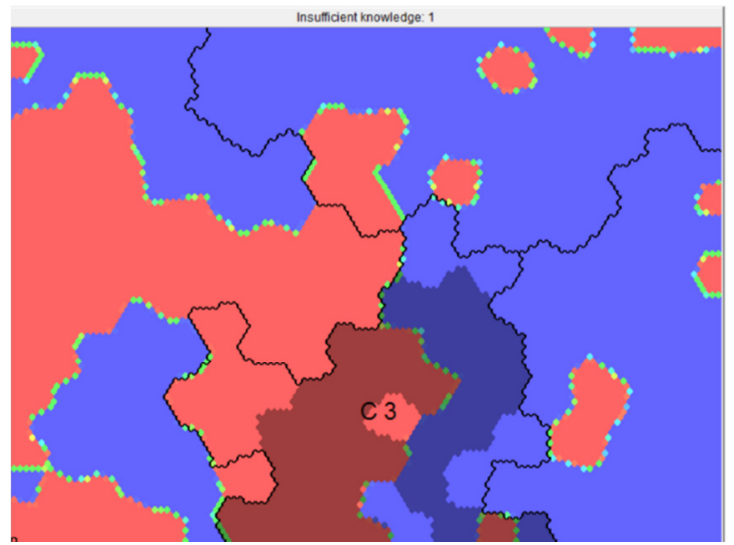

Figure 22 - Insufficient Knowledge Map

\section{Discussion}

\subsection{Main Clusters Interpretation}

The analysis of the maps indicate an intricate combination of factors contributing to the major accidents contained in the MATA-D database, including the significance of the human factors to the undesirable outcome. Previous studies (Graeber, 1999, McLaughlin et al., 2000, Levenson, 2004) 
using different industrial segments as a data source also emphasised the importance of considering human issues when assessing risk, relating between $70 \%$ to $80 \%$ of accidents to some kind of operator error. Therefore, it seems to be clear that a satisfactory risk assessment study must take into account the relationship between humans, technology and organisations to convey realistic scenarios. Otherwise, the safety analysis will not offer a trustworthy dimension of the major hazards that industrial facilities are exposed throughout their lifecycle.

So why scarce attention, especially if compared with the analysis of technical systems (Hollywell, 1996), has been paid to human factors in risk studies? When analysing occupational risk assessments, Cuny \& Lejeune (2003) pointed out some problems to consider the human influence, particularly the preparation of data for processing and the estimation of probabilities to feed deterministic approaches. The complexity of organisational interfaces and the variability of human behaviour also make a sociotechnical system modelling a challenging task, maybe explaining the reason behind the disproportionate focus on purely technical aspects and discrete components in risk evaluation.

The interpretation of the maps enables the possibility of considering the whole range of contributors without previous assumptions of their conjectural importance, focusing on their interactions and on the disclosure of tendencies, instead of concentrating on individual factors. The application of the SOM algorithm and the joint analysis of maps highlighted topographical areas containing similar interfaces, allowing a targeted examination of the genesis of the MATA-D accidents and the development of an attribute checklist with the most frequent observations. Some of these interfaces will be illustrated with the accident narratives as positioned in the map, all accessible through the MATA-D database.

An analysis of Cluster 1 accidents from area 1A (Figure 8) indicates that these events are related to situations where components were designed and implemented on an individual fashion, rather than as a holistic system. Consequently, safety studies failed to adequately address risks related to the system interaction with the environment as well as possible interferences among individual components. The shortcomings in design, procedures, quality and task allocation joined the loss of situational awareness during operation, and insufficient theoretical knowledge led to the misperception of risks. A practical example of this tendency was the widely-known Varanus Island incident in June 2008 (Bills \& Agostini, 2009), when a pipeline rupture and explosion caused a shortage in the gas supply for Western Australia, resulting in 3 billion Australian dollars in economic losses. In summary, the lack of an integrated approach to design and risk management led to problems in the cathodic protection system, most likely due to electrical interferences from adjacent pipes and other structures, causing alternating current corrosion. The assumption that safeguards are always active and the sense that their failures are unconceivable are also patterns observed within the grouping.

Accidents within area 1B (Figure 9) presented situations where process changes undermined the original recommendations from risk assessment studies. Equipment or system replacements, product modifications and procedures updates lacking a proper hazard evaluation (or management of change) enabled the deterioration of the system. The necessary training to operate under the new conditions was also insufficient, causing a human performance failure. 
The shadowed region 1C (Figure 10) contained many events where seemingly minor maintenance issues, i.e. keeping vessels and pipes free of deposits, consumable parts (e.g. filters) replacements, lubrication and calibration, drains obstruction and dust/particles accumulation, were combined with quality problems, task allocation issues, design shortcomings and inadequate procedures to generate a major failure.

Figures 11 and 12 highlighted the map regions where communication problems attained their highest incidence, mostly combined with task allocation issues (Figure 13). These events were prone to poor communication between workers, which was polluted by background noise (mainly alarms and usual process sounds) or by the low quality of the transmission. Deficiencies to report to supervisors some unusual situations observed in the process plant and to convey important information from hazard studies to the personnel were frequent within this grouping. In addition, data transfer from paper to computer-based systems, incorrect coding and poor communication between shifts were risk-increasing factors commonly observed.

Through the results shown in Figures 13 and 14, it is possible to scrutinise a few regions where inadequate task allocation was not as relevant as in the rest of the cluster. Nonetheless, communication issues tended to interact with person-related issues such as a Cognitive Bias, particularly when critical information was not communicated, supporting an illusion that actions taken were sufficient to control the situation, or when actions were constrained by a strong (and wrong) assumption of the current system status. An example extracted from these regions would be the 2011 helicopter crash in Missouri (NTSB, 2013) during a patient transfer from one hospital to another, which resulted in 4 fatalities. The Pilot knew that he has misinterpreted the fuel level to some extent (he reported $26 \%$ or 45 minutes of fuel in the pre-flight check, but post-accident investigation indicated only $18 \%$, or a 30 -min autonomy), but his alternative refuelling plans were constrained by the hypothesis that he was able to reach a reach a station 34 minutes away from the departure point. Maintaining visual contact with the refuelling point (3-minute distance) when the gauge indication approached to zero, the pilot sustained his course (instead of landing immediately) until fuel exhaustion. A communication with qualified land staff (available at the Operational Control Centre) would have recognised his plans as inadequate. Other interesting tendencies where also identified in the cluster region, such as having the attention caught by phone calls or texting in portable devices.

Cluster's 3 erroneous actions and cognitive functions' frequencies are generally higher than in any other grouping, especially the most complex ones, involving the need for mental planning. These human-related factors merged into design shortcomings, equipment failures and quality control issues. A tendency to underperform under non-standard operations (e.g. start-up or partial plant operation) was also observed, repeatedly combined with training issues (Figures 21 and 22). Cases where an equipment failure caused a shutdown, and operators focused on fixing the equipment and restarting it without further consideration are recurrent in this grouping. Some of the common failure modes observed are: (i) catastrophic failures due to the hot flow of products into cold pipes and vessels (brittle fractures); (ii) valves and seals which were damaged or gone partially closed/opened during the operation halt and were not inspected (a quality control problem) before the restart; and (iii) omissions to realign valves and restart control/signalling/alarm systems. 
The grouping also contained some regions where insufficient information from supervisory control and data acquisition systems shaped human erroneous actions (Figures 15, 16 and 17). The growing dependence on information systems is a pattern to be considered when assessing hazards, thus validation schemes must verify if the risk growth due to inadequate/unsatisfactory human-machine interfaces is carefully addressed. The lack of direct indications of problems; panels not providing accurate process overviews; information that is not displayed in relevant places (e.g. in the control room and/or locally); general/critical alarms not taking precedence in relation to local, less important, alarms; delays in the information presented, undermining operators' efforts to diagnose system status; and incorrect information display are some of the human-machine interface problems extracted from Cluster 3.

\subsection{An Attribute List for Risk Assessment Validation}

A safety study generally comprises a planning process (describing the context, regulatory requirements, scope of the study, risk acceptance criteria etc), a hazard identification phase, a risk assessment (e.g. events frequencies, reliability, event modelling, consequences, level of risk estimation) and a final report (e.g. presentation of results, uncertainties appraisal, recommendations, study quality assurance), to generate input to the decision-making process.

The analysis of the common patterns supported by the application of the SOM algorithm enables the translation of the most important observations into a checklist to validate risk studies. Accident tendencies disclosed by the analysis of the maps are now converted into a verification list comprising common hazards, major risks and shortcomings involving interfaces between humans, technology and organisations. A comprehensive semantics will be applied, in order to facilitate the direct application of the list or the integration with existing verification schemes.

Table 3 - Checklist for risk studies validation

\begin{tabular}{|c|c|c|c|c|}
\hline No. & Item & Yes & No & $n / a^{*}$ \\
\hline 01 & $\begin{array}{l}\text { Were the premises, hypothesis and justifications for the chosen design concept } \\
\text { clearly stated? Was a safer known alternative/approach to achieve the same } \\
\text { objective discussed? }\end{array}$ & & & \\
\hline 02 & $\begin{array}{l}\text { Are the underlying basis and limitations of the method, the origin of the input data } \\
\text { and further assumptions (e.g. duration of an event, flammable vapour clouds } \\
\text { expected drifts, maximum spill size, release composition) that support } \\
\text { probabilities, scenarios and results clearly stated? Are they consistent? }\end{array}$ & & & \\
\hline 03 & $\begin{array}{l}\text { Are events' frequencies used in probabilistic risk analysis reliable? Are they used } \\
\text { exclusively when historical data is comparable (e.g. same operation type, facility } \\
\text { or equipment)? Would alternative approaches (e.g. non-frequentist) be more } \\
\text { suitable to estimate the events' likelihood in the study case (e.g. no sufficient past } \\
\text { experience or previous operation data)? }\end{array}$ & & & \\
\hline 04 & $\begin{array}{l}\text { Although some regulations prescribe periodic reviews to risk studies, there is a } \\
\text { tendency that assessments may fall in disuse due to people, process or } \\
\text { environmental changes in between revision deadlines. Modifications usually lead } \\
\text { to a management of change and some sort of risk analysis, but more complex, } \\
\text { previous deeper safety studies are not revisited at this point. Are design } \\
\text { verifications, as-builts, production checks, field data collection or other } \\
\text { approaches required to confirm/maintain trust on the major/approved risk study } \\
\text { throughout the facilities' lifecycle, instead of using a rigid deadline for review? }\end{array}$ & & & \\
\hline
\end{tabular}




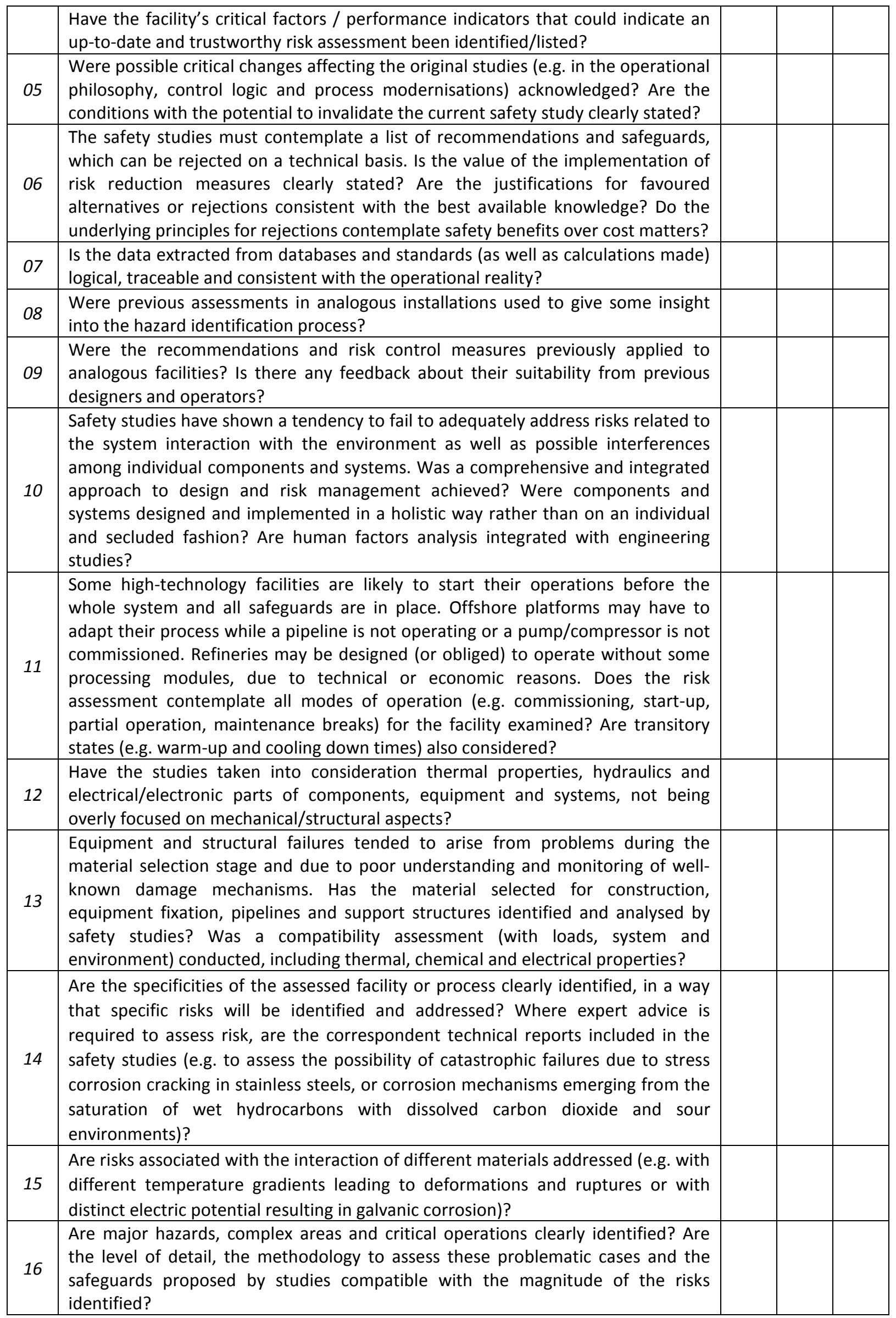




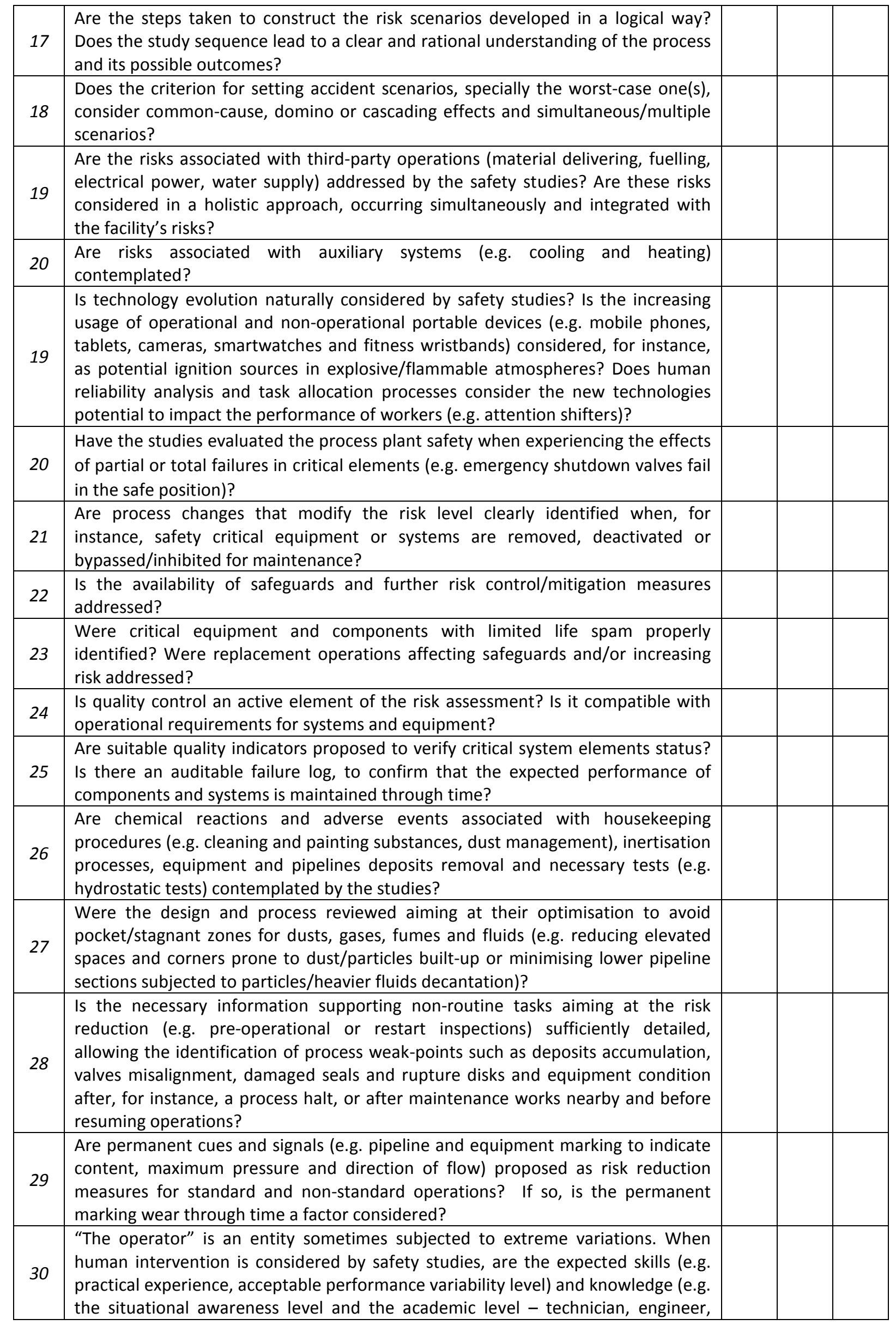




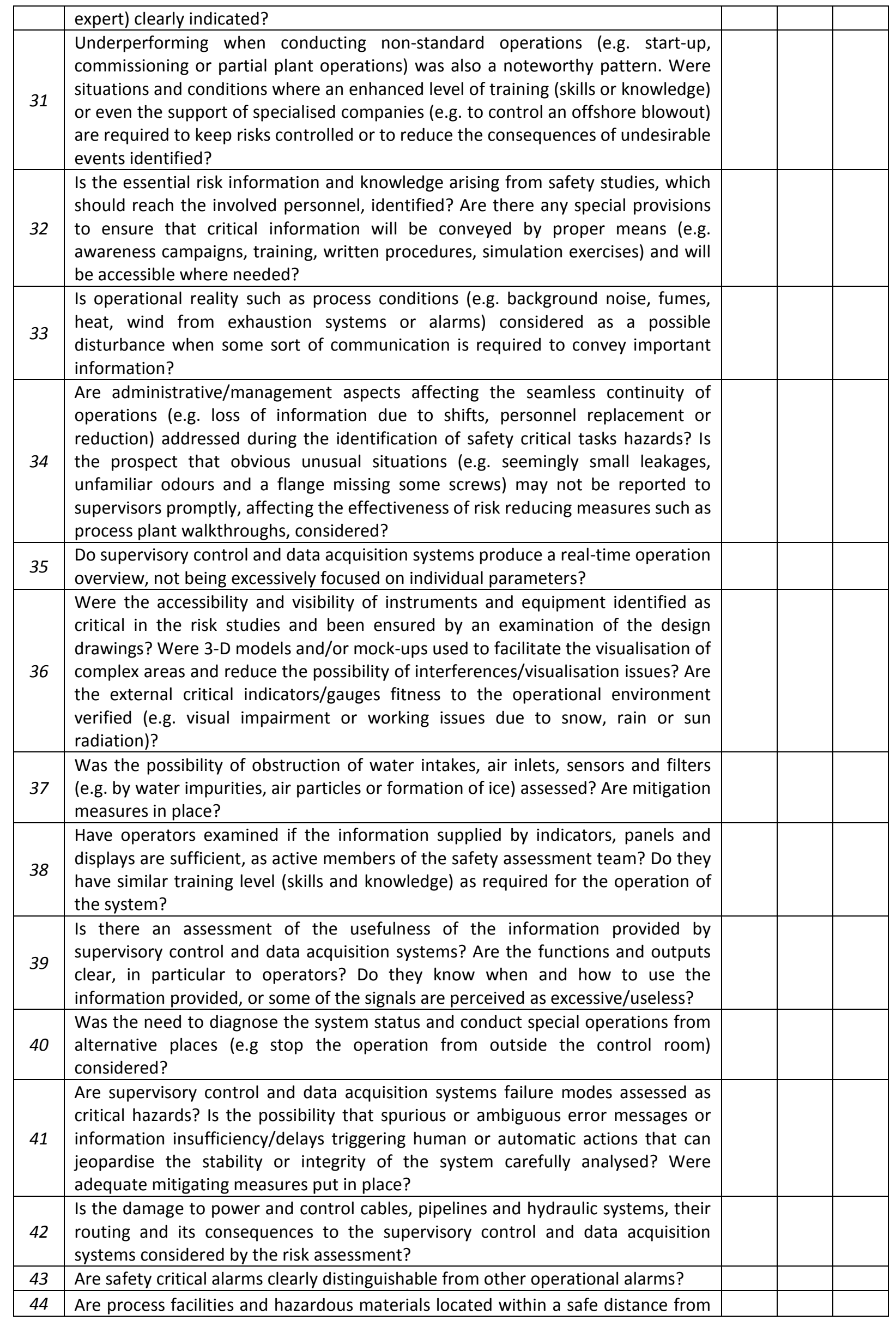




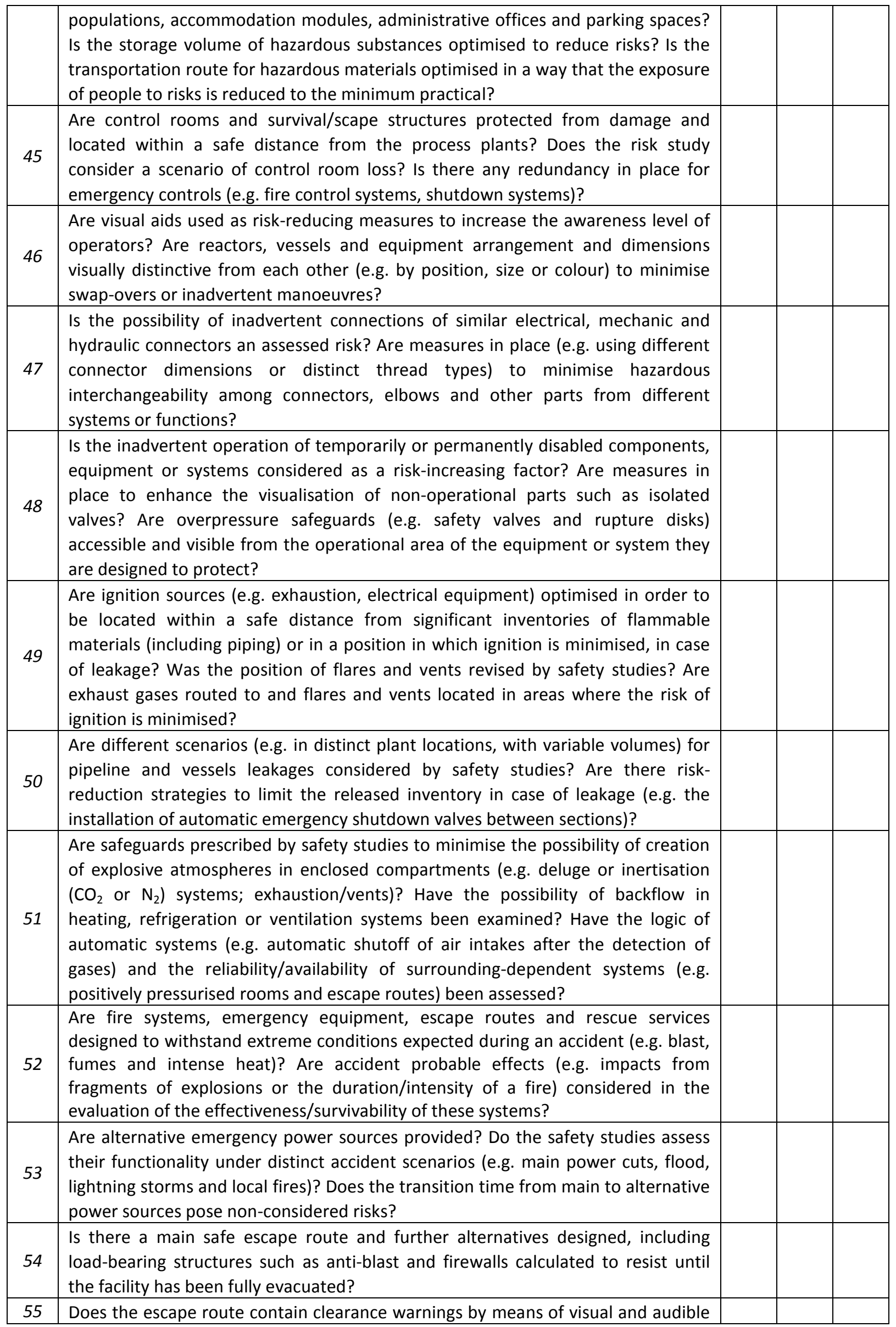




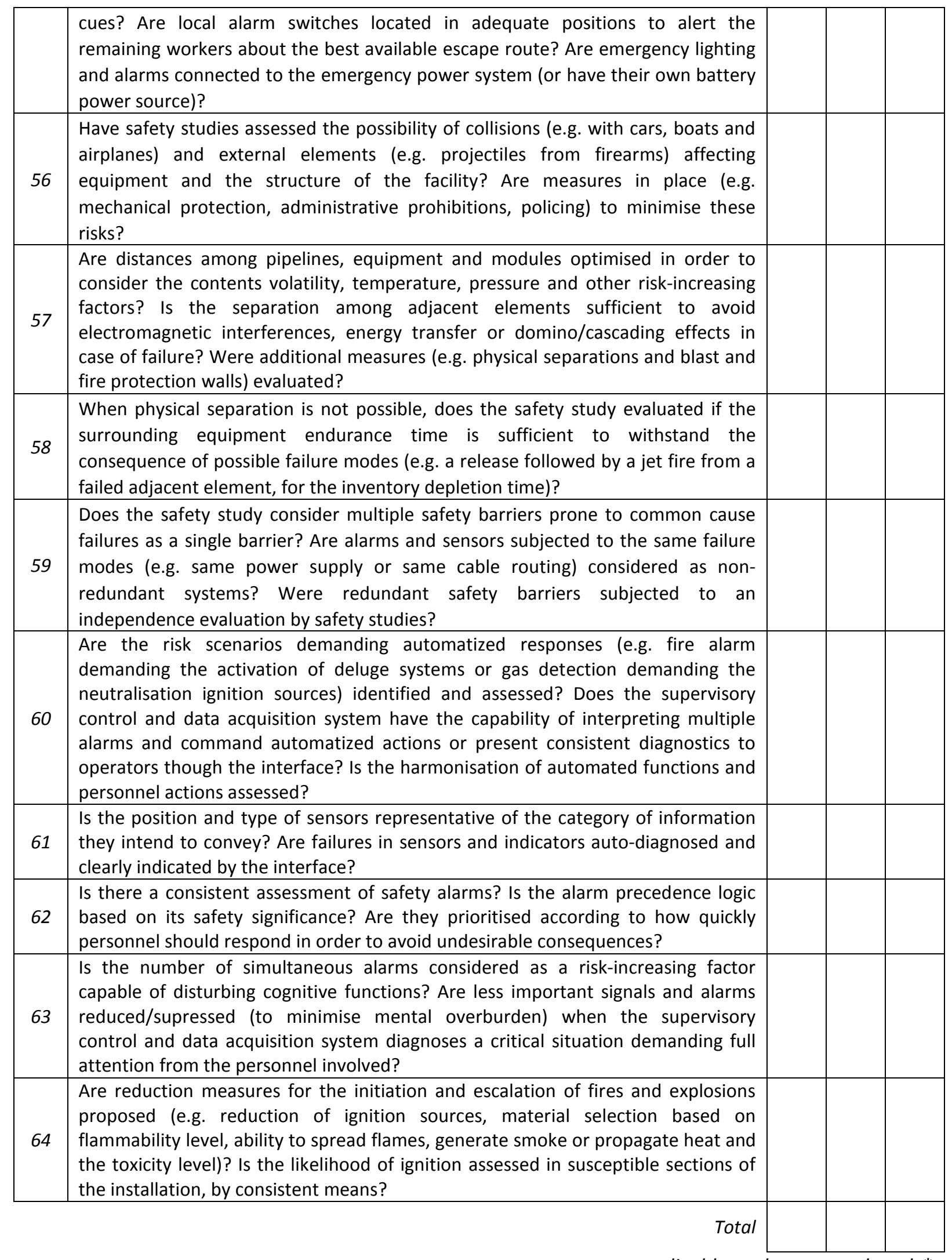

non-applicable to the assessed study*

A large number of positive answers represents a safety study that intrinsically contains solutions for the interface problems encountered in the MATA-D scenarios, which caused major disasters in hightechnology systems. Negative answers indicate weaknesses in the safety study, which should be 
addressed in order to improve trust. For items not relevant or not related to the assessed installation or system, a neutral answer (non-applicable) should be given. After confirming that the major interface problems raised by the list were addressed, the safety study can be seen as robust, from a "lessons learned" perspective.

\section{Conclusions}

Validation schemes must analyse proposed risk reduction measures, taking into consideration that systems are dynamic. Assumptions such "as good as new" systems/equipment, perfect procedures and faultless operators are accurate only on paper, and should be challenged by verifiers. The discussion chapter presented a 64-item attribute list which enables this debate and exposes possible shortcomings, address major hazards and stimulates improvement. The objectives are to give impetus to broader considerations about risk in real projects and raise the discussion about the implementation or dismissal of recommendations and solutions, enabling the dialogue among stakeholders and bringing transparency to the whole process.

Also, the prime attribute of a project is its feasibility, which means cost. This attitude is absolutely normal and engrained in our social behaviour (Does anybody check safety records before booking a flight, or the price is the first - sometimes the only - attribute considered in the decision-making process?). Therefore, promoting the coexistence and balance between economic aspects (i.e. resources, budget) and safety performance is the ultimate goal pursued by risk managers. It is a permanent persuasion exercise for which the current research intend to contribute, by developing means to enlighten stakeholders to consider a wider picture of risk.

The problem of trust in risk management and risk validation is not surprising at all. Risk assessment is a complex and multidisciplinary matter, and there is no such thing as a definite standard reference on how to perform a safety study. Distinct techniques and approaches are not mutually exclusive and should be simultaneously used, making the development of a single validation method or procedure hardly possible. However, the most import outcome of a risk study is to support the decision-making process. Hence, it must be able to communicate risks to stakeholders, addressing potential problems and solutions in a clear way, and using visual aids such as maps can help tackling this challenge.

In this regard, the conversion of the MATA-D dataset into self-organised maps and their subsequent interpretation successfully converged into a comprehensive checklist containing items representing major accident tendencies, to be verified against risk studies and to help developing confidence that critical issues were taken into consideration. These concerns arose from shortcomings in many different industrial segments, also promoting an inter-industry exchange of valuable accident lessons. The questions can be easily traced back to regions in the maps, and practical examples of flawed interfaces between humans, technology and organisations can be extracted, in order to illustrate the possible adverse effects of not dealing with specific conditions. The 2-D SOM maps can be used to communicate and describe complex interfaces to a broader public in a simpler way, enhancing stakeholder's confidence that genuine strategies to mitigate risks are in place and the study was adequately completed. 
Acknowledging that there is not a single method to validate risk studies, the application of the widest possible range of approaches to stimulate the comparison of alternatives and different experts' opinion can give some insight into how to enhance trust in risk management. This work focused on ensuring that lessons from several past accidents are considered by new risk studies as good engineering practice and a sensible approach to reduce risk, by means of a straightforward risk study validation checklist.

Furthermore, the verification framework can be easily applied by a range of independent reviewers from industry and academia, which could use the checklist output to involve experienced people and develop innovative risk approaches, bringing new ideas and insights to safety studies in a structured way.

\section{Acknowledgements}

This study was partially funded by CAPES [Grant no 5959/13-6].

\section{References}

Aven, T., 2013. On the meaning of the black swan concept in a risk context, Safety Science 57: 44-51.

Aven, T., 2015. Implications of black swans to the foundations and practice of risk assessment and management, Reliability Engineering and System Safety 134: 83-91

Baysari, M., McIntosh, A. and Wilson, J. 2008. Understanding the human factors contribution to railway accidents and incidents in Australia, Accident Analysis and Prevention 40: 1750-1757.

Bellamy, L.J. et al., 2007. Storybuilder-A Tool for the Analysis of Accident Reports. Reliability Engineering and System Safety 92: 735-744.

Bellamy, L.J. et al., 2013. Analysis of underlying causes of investigated loss of containment incidents in Dutch Seveso plants using the Storybuilder method, Journal of Loss Prevention in the Process Industries 26: 1039-1059.

Bills, K \& Agostini, D., 2009. Offshore petroleum safety regulation - Varanus Island Incident Investigation. Government of West Australia. ISBN: 978-1-921602-56-6

Blajev, T. 2002. SOFIA (Sequentially Outlining and Follow-up Integrated Analysis) Reference Manual. Brussels: EATMP Infocentre.

British Petroleum., 2010. Deepwater Horizon - Accident Investigation Report, 8 September 2010 [Online]. Available from: http://www.bp.com/content/dam/bp/pdf/sustainability/issuereports/Deepwater Horizon Accident Investigation Report.pdf (Accessed 25 September 2016).

Bureau of Ocean Energy, Management, Regulation and Enforcement (BOMRE)., 2011. Report regarding the causes of the April 20, 2010 Macondo well blowout [Online]. Available at: https://www.bsee.gov/sites/bsee.gov/files/reports/blowout-prevention/dwhfinaldoi-volumeii.pdf (Accessed 25 September 2016). 
Center for Catastrophic Risk Management (CCRM)., 2011. Final Report on the Investigation of the Macondo Well Blowout [Online]. Available at: http://ccrm.berkeley.edu/pdfs papers/bea pdfs/dhsgfinalreport-march2011-tag.pdf (Accessed 25 September 2016).

Cohen, M., March, J. \& Olsen, J., 1972. A Garbage-Can Model of Organisational Choice, Administrative Science Quarterly 17(1): 1-25.

Cuny, X. and Lejeune, M., 2003. Statistical modelling and risk assessment, Safety Science 41: 29-51.

Davis, G., Wanna, J., Warhurst, J. \& Weller, P. 1998. Public Policy in Australia. $1^{\text {st }}$ edn. Sydney: Allen \& Unwin.

Doell, C., Held, P., Moura, R., Kruse, R., and Beer, M., 2015. Analysis of a major-accident dataset by Association Rule Mining to minimise unsafe interfaces, Proceedings of the International Probabilistic Workshop (IPW2015), Liverpool, UK, November 4-6, 2015.

European Safety, Reliability and Data Association (ESReDA), 2015. Barriers to learning from incidents and accidents [Online]. Available from: http://esreda.org/wpcontent/uploads/2016/03/ESReDA-barriers-learning-accidents-1.pdf (Accessed 25 September 2016).

Evans, A., 2011. Fatal train accidents on Europe's railways: 1980-2009, Accident Analysis and Prevention 43: 391-401.

Grabowski, M. \& Roberts, K., 1997. Risk Mitigation in Large-Scale Systems: lessons from high reliability organisations. California Management Review 39(4): 152-162.

Graeber, C., 1999. The Role of Human Factors in Aviation Safety in Aero Magazine QTR_04 1999 (p. 23-31). The Seattle: Boeing Commercial Airplanes Group.

Heinrich, H., Peterson, D. \& Roos, N., 1980. Industrial Accident Prevention. 5th edn. New York: Mcgraw-Hill.

Hollnagel, E. 1998. Cognitive Reliability and Error Analysis Method. Oxford: Elsevier Science Ltd.

Hollywell, P.D., 1996. Incorporating human dependent failures in risk assessments to improve estimates of actual risk. Safety Science 22: 177-194.

Kohonen, T., 2001. Self-Organizing Maps. 3rd ed. Berlin: Springer.

Kohonen, T., 2013. Essentials of the self-organizing map, Neural Networks 37: 52-65.

La Porte, T., \& Consolini, P. 1998. Theoretical and operational challenges of high reliability organisations: air traffic control and aircraft carriers. International Journal of Public Administration, 21 (6-8): 847-852

Leveson, N., 2004. A new accident model for engineering safer systems, Safety Science Journal 42: 237-270. 
Leveson, N., 2011. Applying systems thinking to analyse and learn from events, Safety Science Journal 49, 55-64.

Leveson, N., 2012. Engineering a safer world: systems thinking applied to safety. Cambridge Massachusetts Institute: The MIT Press.

Licu, T. et al. 2007. Systemic Occurrence Analysis Methodology (SOAM) - A "Reason"-based organisational methodology for analysing incidents and accidents, Reliability Engineering and System Safety 92: 1162-1169.

McLaughlin, T., Monahan, S., Pruvost, N., Frolov, V., Ryazanov, B. \& Sviridov, V., 2000. A Review of Criticality Accidents. New Mexico: Los Alamos National Laboratory

Moura, R., Beer, M., Patelli, E., Lewis, J. \& Knoll, F., 2015a., Learning from Accidents: Analysis and Representation of Human Errors in Multi-attribute Events, Proceedings of the 12th International Conference on Applications of Statistics and Probability in Civil Engineering, ICASP12, Vancouver, Canada, July 12-15, 2015.

Moura, R., Beer, M., Doell, C., Kruse, R. 2015b., A Clustering Approach to a Major-Accident Data Set: Analysis of Key Interactions to Minimise Human Errors, Proceedings of the 2015 IEEE Symposium Series on Computational Intelligence (SSCI2015), Cape Town, South Africa, December 8-10, 2015.

Moura, R., Beer, M., Patelli, E., Lewis, J. \& Knoll, F., 2016. Learning from major accidents to improve system design, Safety Science 84: 37-45.

Moura R., Beer, M., Patelli, E. \& Lewis, J., XXXX. Learning from major accidents: graphical representation and analysis of multi-attribute events to enhance risk communication, Safety Science XX: XXXX-XXXX. [Minor review submitted to the Journal on 29 September 2016].

National Transportation Safety Board (NTSB)., 2013. Crash Following Loss of Engine Power Due to Fuel Exhaustion, Air Methods Corporation, Eurocopter AS350 B2, N352LN, Near Mosby, Missouri, August 26, 2011. Aircraft Accident Report AAR-13/02. Washington, DC: NTSB.

Nielsen, DS. 1971. The cause/consequence diagram method as a basis for quantitative accident analysis. Ris $\varnothing-\mathrm{M} 1374$.

Paté-Cornell, M., 2012. On "Black Swans" and "Perfect Storms": risk analysis and management when statistics are not enough, Risk Analysis 32 (11): 1823-1833.

Perrow, C., 1984. Normal Accidents: Living With High-Risk Technologies. New York: Basic Books.

Rasmussen, J., 1997. Risk management in a dynamic society: a modelling problem, Safety Science 27: 183-213.

Reason, J., 1990. Human Error. Cambridge: Cambridge University Press.

Reason, J., 1997. Managing the Risks of Organizational Accidents $1^{\text {st }}$ ed. Farnham: Ashgate Publishing Ltd.

Roberts, K. 1990. Some Characteristics of one type of high reliability organizations. Organization Science 1(2): 160-176. 
Sagan, S., 1993. The Limits of Safety: organisations, accidents and nuclear weapons. New Jersey: Princeton University Press.

Shappell, S., et al. 2007. Human Error and Commercial Aviation Accidents: an analysis using the human factors analysis and classification system. Human Factors 49(2): 227-242.

Skogdalen, J., Vinnem, JE., 2012. Quantitative risk analysis of oil and gas drilling, using Deepwater Horizon as case study, Reliability Engineering and System Safety 100: 58-66.

Taleb, N., 2007. The Black Swan: The Impact of the Highly Improbable. $2^{\text {nd }}$ Ed. York: Allen Lane.

Ultsch, A. 1993. Self-organizing neural networks for visualization and classification. In: Opitz, O., Lausen, B., Klar, R. (eds.). Information and Classification. Berlin: Springer: 307-313.

United States Chemical Safety Board (US-CSB)., 2016. Investigation Report - explosion and fire at the Macondo well [Online]. Available at: http://www.csb.gov/macondo-blowout-and-explosion/ (Accessed 25 September 2016).

United States Coast Guard (USCG)., 2010. Report of Investigation into the Circumstances Surrounding the Explosion, Fire, Sinking and Loss of Eleven Crew Members Aboard the Mobile Offshore Drilling Unit Deepwater Horizon [Online]. Available at: https://www.bsee.gov/sites/bsee.gov/files/reports/safety/2-deepwaterhorizon-roi-uscg-volume-i20110707-redacted-final.pdf (Accessed 25 September 2016).

Zuijderduijn, C., 2000. Risk management by Shell Refinery/Chemicals at Pernis, The Netherlands. EU Joint Research Centre Conference on Seveso II Safety Cases, Athens. 